J. Lake Sci. (湖泊科学), 2017, 29(6): 1279-1299

DOI 10. 18307/2017. 0601

(C) 2017 by Journal of Lake Sciences

\title{
长江的生物多样性危机一一水利工程是祸首,酷渔乱捕是帮凶"
}

\author{
谢 平 $^{1,2}$ \\ (1: 中国科学院水生生物研究所东湖湖泊生态系统试验站, 武汉 430072) \\ (2: 青海大学省部共建三江源生态与高原农牧业国家重点实验室, 西宁 810016)
}

\begin{abstract}
摘 要: 长江是我国第一大河流, 全长达 $6300 \mathrm{~km}$. 长江是一条生命之河, 它的活力来自于干流、支流、湖泊和湿地的血 脉沟通形成的独特生命系统. 长江流域是世界生物多样性的热点区域, 分布有鱼类 400 余种, 其中纯淡水鱼类 350 种左 右, 特有鱼类多达 156 种. 长江中下游是东亚季风气候下形成的洪泛平原区域, 湖泊星罗棋布, 并与江河相连, 生活有 珍稀水生哺乳动物——白暨豚和江豚. 1980s 初中下游湖泊面积约有 $23123 \mathrm{~km}^{2}$. 1950-1970 年间, 沿江大建闸节制, 除 鄱阳湖 $\left(2933 \mathrm{~km}^{2}\right)$ 和洞庭湖 $\left(2625 \mathrm{~km}^{2}\right)$ 等外, 绝大多数湖泊失去了与长江的自然联系, 江湖阻隔使支撑长江鱼类的有 效湖泊面积减少了 76\%.1981 年, 长江上建成了第一个大坝一一葛洲坝; 2003 年, 三峡大坝开始蓄水. 长江干流的渔业 捕捞量从 1954 年的 43 万 $\mathrm{t}$ 下降到 1980s 的 20 万 $\mathrm{t}$, 最后到 2011 年的 8 万 $\mathrm{t}$ (降幅为 $81 \%$ ). 与此完全不同的是, $1950 \mathrm{~s}$ 以 来, 洞庭湖和鄱阳湖的渔产量分别在 $2 \sim 4$ 万 $\mathrm{t}$ 之间徘徊. 长江干流的饵料生物丰度不足两湖的 $1 / 7$, 因此干流对物种的 承载力十分有限, 以鱼为生的白㮣豚和江豚种群的衰退属于情理之中, 加上酷捕误杀, 白暨豚已经灭绝, 江豚也危在旦 夕. 葛洲坝的建设阻挡了鲟鱼和胭脂鱼等的生殖洄游通道, 中华鲟和白鲟的灭绝已近在迟尺. 长江上游建有 1 万多座水 坝，大部分鱼类的生存受到威胁. 根据对长江生物多样性危机成因的粗略估算，节制闸和水电站等水利工程 “贡献”了 $70 \%$, 酷渔乱捕等其它因素 “贡献”了 $30 \%$. 所谓的生态调度、鱼道或人工放流等也难以拯救膏育之疾, 即使在长江干流 十年禁渔也难有根本改观. 如果鄱阳湖和洞庭湖相继建闸, 将使长江中下游的渔业资源量进一步衰退, 江豚的灭绝在所 难免, 其它物种的灭绝将难以预料. 长江在哭泣, 众多的物种需要生态文明的呵护!
\end{abstract}

关键词: 长江;水利工程;生物多样性;鱼类资源;白暨豚;中华鲟

\section{Biodiversity crisis in the Yangtze River:The culprit was dams, followed by overfishing}

\author{
XIE Ping ${ }^{1,2}$ \\ (1: Donghu Experimental Station of Lake Ecosystems, Institute of Hydrobiology, Chinese Academy of Sciences, Wuhan \\ 430072, P.R.China) \\ (2: State Key Laboratory of Plateau Ecology and Agriculture, Qinghai University, Xining 810016, P.R.China)
}

\begin{abstract}
The Yangtze River is the largest river in China, with a total length of $6300 \mathrm{~km}$. The Yangtze River is a river of life, with its vitality from a unique system unifying the main river, branches, lakes and wetlands. It is a key area for biodiversity of the world. The river has ca. 400 species of fishes, of which 156 species are endemic. The middle and lower reaches of the river are a flooding plain formed historically under monsoon climate, having numerous shallow lakes connecting to the river or its branches, with two rare mammals - the freshwater dolphins. In the early 1980s, the lakes had an area of $23123 \mathrm{~km}^{2}$, but during 1950-1970, except Lake Poyang and Lake Dongting, all lakes were isolated artificially by concrete sluices, and ca. 76\% lake area supporting ecologically the river was decreased. In 1981, a large dam, Gezhouba, was built, followed by the Three Gorges Dam in 2003. Total catches in the main river was $4.3 \times 10^{5} \mathrm{t}$ in 1954 , declined to $2.0 \times 10^{5} \mathrm{t}$ in the $1980 \mathrm{~s}$, and further to $8.0 \times 10^{4} \mathrm{t}$ in 2011 (a reduction of $81 \%$ ). In contrast, since the $1950 \mathrm{~s}$, total catches in Lakes Dongting and Poyang fluctuated between $2 \times 10^{4}-4 \times 10^{4} \mathrm{t}$, respectively. Abundance of planktonic preys in the river were less than $1 / 7$ of the adjacent lakes, indicating a week ability to support existence of a large number of species. Thus it is not surprising that Lipotes vexillifer and Neophocaena asiaeorientalis witnessed steady declines in abundance, as both species feed on fishes in the river or lakes, as well as partly by indiscriminated killing by fisherman.
\end{abstract}

* 中国科学院野外站联盟项目 (KFJ-SW-YW026) 和中国科学院 B 类先导科技专项培育项目 (XDPB02) 联合资助. 2017-08-28 收稿;2017-09-02 收修改稿. 谢平(1961 ), 男, 博士, 研究员; E-mail: xieping@ihb.ac.cn. 
Since the day when the Gezhouba Dam was built, Chinese sturgeon and paddlefish doomed the fate of extinction, as their reproductive migration pathway was truncated. In the upper reaches of the Yangtze River, there have more than 10 thousand dams, and the survival of most fish is threatened. As to the causes of the biodiversity crisis in the Yangtze River, water conservancy projects such as gates and hydropower stations contributed ca. 70\%, whereas other factor such as overfishing contributed ca. 30\%. It is impossible to solve the fatal crisis by the so-called flow regulation, or artificial releasing of fingerlings or fishway, and it seems impossible to have a fundamental improvement on the fishery resources in the Yangtze River even fishing is forbidden for ten years. If Lakes Poyang and Dongting are isolated by dams, the fishery resources in the river will further decline, the extinction of the finless porpoise can hardly be avoided, and no prediction can be made for the extinction of other fishes. The Yangtze River is crying, and numerous species need the care of ecological civilization!

Keywords: Yangtze River; water conservancy projects; biodiversity; fish resources; Lipotes vexillifer; Chinese sturgeon

大河流域往往是文明的发源地, 人类文明史也是人与自然、人与河流相互作用的历史 ${ }^{[1]}$. 江河是人类的 母亲——千年来, 人类生于斯, 长于斯, 与江河的关系密不可分, “鸟去鸟来山色里, 人歌人哭水声中” ${ }^{[2]}$. 河流与峡谷构成了美丽的自然景色,千百万年来,滔滔河水在雄伟壮丽的峡谷中奔流不息, 从涓涓小溪到滚 滚洪流……然而, 人类的肆意改造一一水坝,使它们面目全非, 曾经的蜿蜒崎岖与野性奔放不复存在. 我们 人类,特别是年轻的一代,也因此正在失去对大自然美景——幽幽峡谷、滔滔急流——的精神感知, 以及随 之而生的美好回忆、希冀或梦想. 河流的生态价值在于自由流动的河水支撑了由多种多样的物种构成的和 谐的水生态系统. 但是, 在过去的半个世纪, 中国的河流政策却一味地追求河流的利用价值, 因此建设的大 坝超过了 22000 座, 占全世界大坝总数的 46\%, 远远超过世界上任何一个国家 (美国共建了 6500 多座大 坝), 其中巨大的三峡大坝倍受全世界关注 ${ }^{[3]}$.

\section{1 长江一一华民族的母亲河}

\section{1 长江是现代文明的重要支撑}

长江是我国第一、世界第三大河流, 发源于青藏高原唐古拉山主峰, 全长达 $6300 \mathrm{~km}$, 流域面积 $1.8 \times 10^{6}$ $\mathrm{km}^{2}$, 占全国总面积的 $18.7 \%$. 长江流域西高东低, 落差超过 $5400 \mathrm{~m}$,形成三级阶梯的地势,一级阶梯的海拔 $3500 \mathrm{~m}$ 以上, 三级阶梯海拔 $500 \mathrm{~m}$ 以下. 长江水系可划分为干流水系与雅聋江、峮江、嘉陵江、乌江、洞庭湖、 汉江、鄱阳湖、太湖等 8 个支流水系, 长江流域 (不含太湖水系) 最高河流分级数为 6 级, 流域面积不小于 $2000 \mathrm{~km}^{2}$ 或河长不小于 $100 \mathrm{~km}$ 的河流总数为 374 条 ${ }^{[4]}$.

受东亚季风气候的影响, 长江流域雨水丰沛, 年径流量占全国总径流量的 $37.7 \%$. 对洪水, 我们是爱恨 交加. 洪水为我们提供了丰富的再生能源一一水电, 它能缓解化石能源日益枯竭的压力, 因此人们在干支流 的上游修建了数以万计的水电站. 水电毫无疑问是一种清洁能源, 远比燃烧煤炭对大气环境要友好, 并可以 减缓全球气候变暖, 水电也没有核电那样如果泄露会给人类带来毁灭性打击的风险, 因此, 水电具有巨大的 环境效益, 但这并不能抵消其巨大的生态破坏. 长江中下游河湖纵横交错, 是典型的洪泛平原区, 人口密集, 从古至今人类围湖造田, 开叚出无数的良田用于农业生产, 建造了无数高楼大厦为人所居, 人类大修堤坝与 节制闸, 一方面控制洪水泛滥, 另一方面利于在湖泊中的渔业养殖, 其结果是, 除了洞庭湖和鄱阳湖外, 几乎 所有的湖泊都与长江切断了自然联系. 对不能控制的干支流和大型通江湖泊, 长期酷渔滥捕, 尽可能多的获 得动物蛋白. 这一系列人类活动虽然满足了我们巨大的利益需求, 但也使我们付出了沉重的生态代价一 使一些物种纷纷走向灭绝之路.

\section{2 长江是鱼类资源的宝库与渔业的支柱}

据估计,全世界的鱼类大约有 32500 种 ${ }^{[5]}$, 其中淡水鱼类超过 15000 种, 而淡水仅占全球水资源量的 $0.3 \%$, 这反映了淡水环境具有高生产力、丰富的地形多样性以及强烈的地理隔离 ${ }^{[6]}$. 我国有鱼类 3446 种, 其 中淡水鱼类 1452 种. 鱼类的生活形形色色, 大部分鱼类要么在淡水中生活, 要么在海水中生活, 只有不到 $10 \%$ 的洄游鱼类在淡水和海洋两种生境中来回迁徙. 在海洋中生长但需要去淡水中繁殖称为溯河洄游 (如 中华鲟 (Acipenser sinensis) ), 在淡水中生长但需要去海洋中繁殖称为降河洄游 ( 如花鳗鲡 ( Anguilla marmora$t a)$ ). 如果肥育和繁殖的迁徙发生在河湖之间, 就称之为半洄游性鱼类, 一般是在湖泊中肥育, 在河流中产 
卵(如四大家鱼). 还有一些鱼类的生活限于河流的干支流, 只进行相对较短距离的迁徙.

长江水系有鱼类 400 余种, 其中纯淡水鱼类 350 种左右, 特有鱼类多达 156 种 ${ }^{[7]}$. 长江流域的天然捕捞 产量占全国淡水鱼总捕捞的 $63 \% \sim 64 \%$, 是我国淡水鱼最重要的产区 ${ }^{[8]}$. 长江上游干流和主要支流, 均流经 高山峡谷和丘陵地区, 水流湍急, 因此上游的大多数鱼类终生生活于流水环境中, 其形态结构、生理机能和 生态习性均与栖息的流水环境相适应.上游鱼类主要是一些在流水环境中营底栖生活的种类,摄食着生硅 藻和丝状藻类、蜉蝣目、禎翅目、毛翅目的幼虫或稚虫及淡水壳菜等, 许多种类下领具有锐利的角质边缘, 或 是下唇、触须发达, 利于刮食着生藻类或吸食底栖无脊椎动物, 有些种类的胸腹部或口唇部形成吸盘, 可牢 固地吸附于石块上面,不致被水流冲走;还有一些种类则是经常栖息于石缝或洞穴之中 ${ }^{[8]}$.

在金沙江源流段以及川西高原的一些水系, 海拔高, 气候寒冷, 水流湍急, 主要分布有裂腹鱼和条䲝, 它 们通常在峡谷河道的激流中生活, 并不下降到中下游. 在川西高原和川东盆地交接的低山地带、汉江上游和 洞庭湖水系的上游地区, 生活着一些适应水急石滩多的溪河环境的鱼类, 如唇鮡 (Euchiloglanis davidi)、中华 纹胸鮡 (Glyptothorax sinense) 和平䱜鲀科鱼类. 长江通过三峡之后, 进人中下游平原地区, 这里江面宽阔, 水 流平缓, 沿岸湖泊星罗棋布, 水质肥沃, 饵料生物丰富, 且受季风气候的影响, 水位剧烈波动, 这里生活的鱼 类种类繁多, 凶猛鱼类如鳡 (Elopichthys bambosa)、鯮(Luciobrama macrocephalus)、长吻鮠( Leiocassis longirostris)、鲌(Culter) 等, 小型鱼类如鰕虎(Ctenogobius giurinus)、鳑鮍(Rhodeus)、麦穗鱼 (Pseudorasbora parva)、青

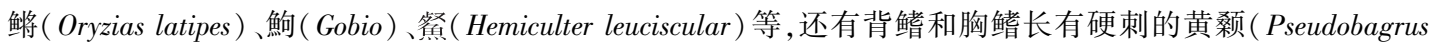
fulvidraco)、背鯺和慰鳍长有硬刺的鲤(Cyprinus carpio)、鲫(Carassius auratus), 以及产漂流性卵的青鱼 (Mylopharyngodon piceus)、草鱼(Ctenopharyngodon idellus)、鲢鱼 (Hypophthalmichthys molitrix)、鲜鱼 (Aristichthys nobilis), 它们在湖泊中肥育, 在长江干支流中越冬与生殖. 在河口地区几乎都是浅海鱼类和咸淡水鱼类, 如 鲋 (Macrura reevesi)、前领间银鱼 (Hemisalanx prognathus) 和暗纹东方鲀 (Takifugu obscurus) 等 $^{\left[{ }^{[9]}\right.}$. 在中下游水 系, 逐步演化出鲢亚科、鲌亚科、鮈亚科、鳑鲏亚科、鲉鮀亚科等新类群及雅罗鱼亚科和鮈亚科的一些特殊种 属, 从而形成了东亚特有的江河平原鱼类区系 ${ }^{[10]}$.

长江水系蕴藏了独特而多样的物种, 为我们提供了丰富的水产品, 这是洪水泛滥的产物, 而我们的过度 需求导致了开放水域中的酷渔滥捕. 洪水虽然对人类来说是灾害, 却能为我们提供宝贵的水电资源, 一方面 我们在中下游大修闸坝以控制洪水泛滥, 另一方面我们对水电的过度追求, 导致长江上游被数以万计的水 坝肢解得零零碎碎. 其结果, 自然原始的长江水生态系统被折腾得面目全非, 物种纷纷濒危, 生物多样性面 临空前的危机. 总体来看, 在长江干支流, 筑坝对鱼类的负面影响可能比河流中的水污染、过度捕捞和生境 破坏要严重得多.

\section{2 长江之歾一一水坝林立}

\section{1 河流连续统一体的瓦解}

水坝使河水中栖息的鱼儿或其它动物的自由被束缚牵制,或食物条件急剧恶化,难逃灭顶之灾一一有 些失去了生长肥育的场所, 有些失去了繁殖之地……其结果, 长江的生物多样性陷人了前所未有的危机, 一

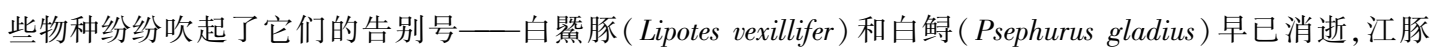
(Neophocaena asiaeorientalis) 和中华鲟日渐稀落……河水中昔日的和谐共振日渐单调木讷, 喧器繁华日趋萧 条死寂. 由鱼儿和豚儿们的生死音符所谱写出的只有在长江中才能听到的独特而和谐的生命乐章永远消失 了. 我们只能眼睁睁地看着旗舰物种一个接一个地消逝了, 问题是, 千百万年来它们一直存在着的!

拦河筑坝将不可避免地改变坝区以及上下游的水文特性,包括洪水脉冲模式、泥沙过程、水温过程等, 这会影响河床冲刷及江( 河) 湖关系等,进而可能显著改变栖息于其中的水生动植物群落,这种改变对一些 高度依赖河流连续统一体或江湖复合系统的水生动物 (特别是鱼类) 来说, 可能会带来致命的后果.

有些鱼类喜欢栖息于急流环境 (无论是摄食还是繁殖), 大坝的建设就会导致它们的衰退. 这导致习惯 了在河流中无拘无束生活的物种突然失去了对它们熟悉的自然进程的感知, 而它们的祖祖辈辈却通过进化 对此予以了固化, 并演变成了独特且难以轻易改变的生态秉性, 藉此物种维持了它们在河流中的历史存在.

德国博物学家海克尔 (Ernst Heinrich,1834-1919 年) 曾有一句名言: “个体发生重演系统发生”. 其实, 
不仅是动物的躯体, 它的习性也在重复着种族的进化历程, 虽然预留了在地史尺度上的对环境变化的适应 性改变,但对人类突如其来的剧烈干扰来说,这种极其缓慢的适应对物种的生存来说就失去了意义.

\section{2 长江复合生态系统的肢解}

长江是由干流、支流及其附属湖泊组成的一个有机整体, 俨似一颗大树一一由树干、树枝及树叶组成, 由于湖泊肥沃, 生产力高, 对长江生物多样性的维持起到了至关重要的作用, 就像树叶对整个树的作用一 样, 没有树叶的光合作用, 树亦难以为继.

$1940 \mathrm{~s}$ 末, 长江中下游湖泊总面积尚有约 $35123 \mathrm{~km}^{2}$, 到 $1980 \mathrm{~s}$ 初只剩下 $23123 \mathrm{~km}^{2}$, 降幅达 $34.2 \%^{[11]}$. 鄱 阳湖面积约为 $2933 \mathrm{~km}^{2}$, 洞庭湖面积约为 $2625 \mathrm{~km}^{2}$. 1950-1970 年间, 长江中下游沿江大建闸节制, 除鄱阳 湖和洞庭湖等外, 绝大多数湖泊失去了与长江的自然联系 ${ }^{[12]}$. 因此, 江湖阻隔使支撑长江鱼类的有效湖泊 面积减少了 76\%, 而干流的饵料稀少. 这相当于把一棵大树上的树叶绝大部分摘光. 1981 年, 长江上建成了 第一个大坝一一葛洲坝, 位于宜昌市三峡出口南津关下游约 $3 \mathrm{~km}$ 处, 总库容量 $1.58 \times 10^{9} \mathrm{~m}^{3} .2003$ 年, 位于 宜昌三斗坪的三峡大坝开始蓄水, 是全世界装机容量最大的水电站, 坝高 $185 \mathrm{~m}, 2010$ 年蓄水至 $175 \mathrm{~m}$, 此时 水库面积约 $1080 \mathrm{~km}^{2}$, 水库平均水深 $70 \mathrm{~m}$, 总库容 $3.93 \times 10^{10} \mathrm{~m}^{3}$. 形象地说, 这相当于把一棵树的主干砍成了 3 截. 人们常说,干壮,枝叶才茂,但是,没了枝叶相连,树干何以能保持生机?

\section{3 水坝之争}

\section{1 利与弊}

水坝建设在发达国家正在减速, 而在发展中国家依然在快速推进, 主要受经济利益的驱动, 因为水利工 程能为人类带来诸多益处一一发电、防洪、航运、供水、渔业、娱乐等, 而对生态的影响则多视而不见. 其实, 筑坝对生态的负面影响亦是多方面的, 如使鱼类失去行为刺激、阻断洄游通道、失去产卵场、卵和幼鱼的存 活率降低、饵料生物减少等等.

长江的水能资源丰富, 上游干支流的梯级电站以及三峡大坝提供的廉价、清洁和可再生能源为国民经 济的发展做出了巨大贡献, 也是我国在践行对 $\mathrm{CO}_{2}$ 减排的国际承诺. 此外, 三峡大坝不仅大大提升了川江的 通航能力 (形成了所谓的“黄金水道”), 还改善了长江中下游特别是荆江河段的防洪能力.

大坝对长江水系产生了一系列的负面生态效应. 在长江干支流中大坝的建设往往会将洄游鱼类的索饵 区和繁殖区割裂开来, 给它们带来致命打击, 因为这样的习性是经过千百万年的演化 (对长江流域的许多物 种来说, 就是适应东亚季风气候及大江大河的水文节律) 而形成的, 难以轻易改变, 体型越大的动物越是如 此, 因为身体的复杂化使它们对环境变化的可塑性大大降低. 一般来说, 与降河洄游的鱼类相比, 溯河洄游 的鱼类可能更容易受到人类活动 (如大坝) 的打击, 因为大坝往往直接破坏了产卵场, 这是最致命的.

大坝建设及其对生态的负面影响也是全球性的. 譬如,在美国华盛顿的埃尔瓦河, 曾经每年有约 40 万 尾鮏溯河产卵, 但建坝之后, 来产卵的鮏不足 3000 尾, 因为它们失去了 $90 \%$ 的产卵场, 虽然后来添加了昂贵 的鱼道, 但也无济于事 ${ }^{[13]}$. 根据 IUCN 的资料, 水坝是近百年来造成全球淡水鱼类近 $1 / 5$ 遭受灭绝、受威胁 或濒危的主要原因, 将近 3/4 的德国淡水鱼和 $2 / 5$ 的美国淡水鱼受到了它的影响 ${ }^{[14]}$. 世界上已几乎没有不 被水坝䈨起来的江河, 自由流淌的江河变成了水库搭起来的台阶, 令人瞠目结舌 ${ }^{[15]}$.

越来越多的国家或地区开始反思以工程为主的治水思路,开始倡导“为河流让出空间”、“为洪水让出空 间”、“建立河流绿色走廊” 等, 以恢复健康完整的河流生态系统及其生态功能 ${ }^{[1]}$.

\section{2 建坝与反坝的较量}

1997 年 3 月, 在巴西 Curitiba 举行了“第一届受水库危害者国际会议”, 14 日,巴西当地的环保团体组织 了“巴西反大型水坝行动日” 游行, 对日益危急的亚马逊河水库滥建问题发出的愤怒之声, 来自 20 个国家及 地区的代表发布了“屈里替巴宣言( Declaration of Curitiba)”, 并宣布每年的 3 月 14 日为世界反水坝日 ( the International Day of Action for Rivers and Against Dams). 在美国, 反坝运动最早的成功案例大部分是由有钱、 有势、闲散并嗜好自然美感的贵族或资产阶级荒野保护者 (也是国家公园最早的倡导者) 所领导, 1956 年, 在他们的影响下, 回声谷公园的高坝计划被成功地否决, 就美国水库工业史而言, 这至少终结了水库兴建者 予取予求的时代. 
1990-2015 年期间, 美国已经拆去了 900 座大坝 (包括了埃尔瓦河上的两座水坝), 今后计划每年拆除 50 60 座 ${ }^{[16]}$. 根据美国地球之友 (Friends of the Earth) 、美国河流组织 (American Rivers) 和鲑鳟类保护协会 (Trout Unlimited) 的统计数据,自 1912-2013 年期间,美国共拆坝 1108 座,其中 2000 年后拆除了 638 座,拆 坝速度明显加快, 关于拆坝的原因, 综合考虑生态、经济与安全三方面因素的占 $43.9 \%$, 生态恢复占 $34.4 \%$, 经济因素占 $12.9 \%$, 安全因素占 $7.2 \%$, 因此,生态恢复是美国闸坝拆除的最主要驱动因素 ${ }^{[17]}$.

但是, 支持建坝者却宣称, 美国只是拆除了几百座年久失修、不符合安全管理标准和废弃不用的小型水 坝, 其实我国每年都有上百座小型水坝退役, 数量远多于美国, 此外, 一些发达国家由于水电资源开发殆尽, 已无坝可建, 绝不是说水坝的作用遭到了否定 ${ }^{[18]}$. 还有人宣称, “不能以 “生态”名义在关注 “鱼、树、草” 的时 候忘记了“以人为本”……发达国家的实践证明: 水电和水资源开发程度越高, 经济越发达, 生态环境也越 好……欧美国家从来没有进入 “拆坝时代”, 反而在不断巩固、加强大坝的建设” ${ }^{[19]}$. 建坝派与反坝派一直都 在激烈交锋,有时甚至相互进行人身攻击. 这其实已不是对错的问题, 是价值观的对决!

\section{4 长江的生物多样性危机一一源头到河}

长江的生物多样性问题是全域性的, 从高寒的源区一直到流人东海的河口. 中下游的旗舰物种纷纷告 急一一白暨豚已经功能性灭绝, 江豚也危在旦夕, 中华鲟和白鲟的灭绝趋势已无法挽回. 上游的形势更加危 急一一据统计, 长江的特有鱼类主要分布在上游, 而上游特有鱼类的近 $40 \%$ 为受威胁物种 ${ }^{[20-22]}$. 面对如此生 物多样性危机, 我们怎能熟视无睹?

\section{1 源头一一生态脆弱}

长江源头由沱沱河 (西源)、当曲 (南源) 和楚玛尔河 (北源) 组成, 它们汇人通天河. 源区河流湿季像大 河, 冬季像小溪, 甚至被完全冰冻. 长江源区平均海拔 $4500 \mathrm{~m}$ 以上, 年平均气温不到 $1^{\circ} \mathrm{C}$, 有时 $7-8$ 月份也 会飘起飞雪 ${ }^{[23]}$. 高寒缺氧, 自我恢复能力差, 是生态的脆弱地带. 在源头河流中, 由于气温低, 鱼类的生长期 短, 生长缓慢, 繁殖力低, 加上分布较为狭窄, 对人类的干扰 (建坝、酷渔等)十分脆弱, 容易濒危. 通天河中的 长丝裂腹鱼 (Schizothorax dolichonema)、裸腹叶须鱼 (Ptychobarbus kaznakovi)、中华鮡 ( Pareuchiloglanis sinensis)、黄石爬鮡( Euchiloglanis kishinouyei) 等已被列入《中国濒危动物红皮书》和《中国物种红色名录》. 譬如, 由于近年内地人员进藏酷渔滥捕, 可分布至沱沱河的裸腹叶须鱼其种群数量急剧下降, 长丝裂腹鱼、中华鮡 和黄石爬鮡已被列为濒危物种. 其实, 藏民们从不打鱼、吃鱼, 视鱼为神, 视湖为圣. 由于海拔高, 气温低, 在 源区河流中生活的高原鱼类,需进行季节性迁徙或躲人深潭, 以度过寒冷的冰封期. 如果源区的一些生境消 失,这些鱼类的生存空间亦被相应地压缩.

\section{2 上游一一水电疯狂}

自葛洲坝水利枢纽建成之后, 长江上游的水电开发开始进人无序状态, 而如火如茶的长江经济带建设 使之更为疯狂, 原本奔腾流畅的长江, 变成了一个密密麻麻的水库群, 被数以万计的 “梯田” 景观所取代, 其 结果是一一个完整健康的河流生态连续统被肢解成了无数零散的碎片 (图 1), 很多上游的特有鱼类濒临 灭绝 ${ }^{[24]}$. 长江上游受威胁物种数达 79 种, 位居全国各大河流之首, 长江中下游的受威胁物种也有 28 种 (图 2).

\section{3 中下游——枝叶断裂}

长江中下游湖泊与湿地既提供了丰富的水产品, 也提供了不少肥沃的良田以及建设用地. 同时因为这 里也是我国洪涝灾害的集中分布区,与此相关的水利设施的建设为保障人民生命财产的安全做出了贡献.

长江中下游的干支流曾与无数的浅水湖泊交织成一个复杂偶联的生态网络,很多鱼类特别适应于在季 风气候与洪水泛滥中繁衍生息, 养成了很多与洪水关联的繁殖习性. 自 1950s 起, 除洞庭湖、鄱阳湖外, 其它 湖泊均与长江割裂开. 由于湖泊中的㙁料丰富, 而干流的饵料贫㾉, 江湖阻隔导致了干流渔业资源的迅速衰 退: 长江干流的渔业捕捞量从 1954 年的 $4.3 \times 10^{5} \mathrm{t}$ 下降到 $1980 \mathrm{~s}$ 的 $2.0 \times 10^{5} \mathrm{t}$ (降幅为 $53 \%$ ), 最后到 2011 年 的 $8.0 \times 10^{4} \mathrm{t}$ (降幅为 $81 \%$ ). 1964-1965 年长江干流四大家鱼年均产卵量高达 1150 亿, 到 1981 年下降到了 170 亿, 降幅达 $85 \%$, 这一年正是葛洲坝截流之年 ${ }^{[26-27]}$. 对中下游干流渔业资源的大幅衰退而言, 江湖阻隔 难各其责,虽然酷渔滥捕也起到了落井下石的作用. 


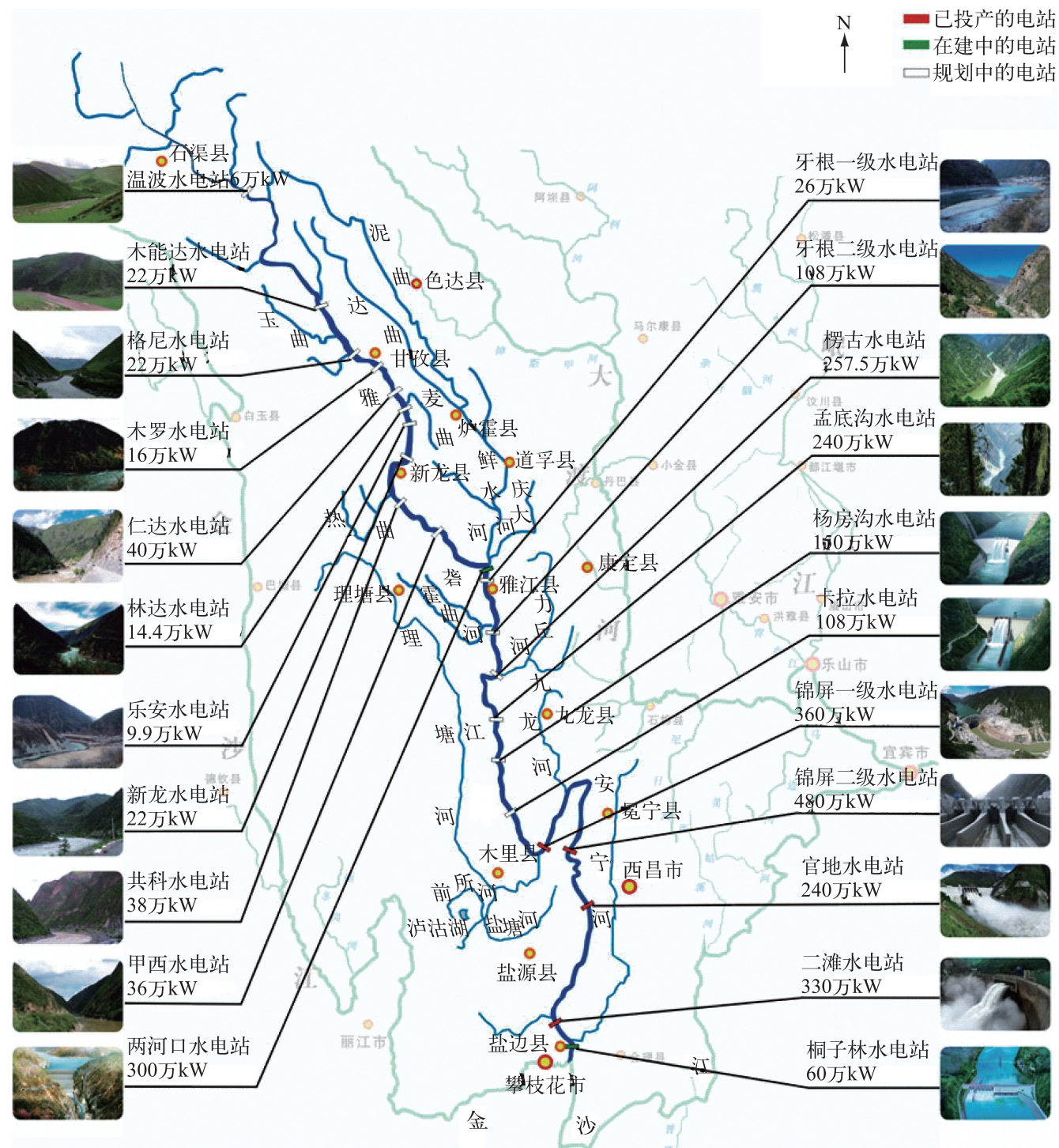

图 1 雅聋江干流全长 $1571 \mathrm{~km}$, 天然落差 $3830 \mathrm{~m}$,已建、在建和规划建设 20 多个梯级电站, 2025 年将实现装机 $3.0 \times 10^{7} \mathrm{~kW}$, 相当于 1.5 个三峡水电站(来源: 中国能源报, 2014-07-21(22))

Fig.1 Yalong River has a total length of $1571 \mathrm{~km}$, and a natural drop of $3830 \mathrm{~m}$. More than

20 cascade hydropower stations (most have been built), and 30 million $\mathrm{kW}$ will be installed in 2025, equivalent to 1.5 times of the Three Gorges Hydropower Station (cited from China Energy News, 2014-07-21)

以下分析支持上述结论. 为了评估长江干流本身对栖息于其中的物种支撑能力到底有多大, 需知晓长 江干流的水域面积以及其生物生产力, 这样才能与连通湖泊进行比较. 长江全长有 $6300 \mathrm{~km}$, 但宽度不一, 从 几十米到几千米不等. 源区至金沙江的河段一般都只有数十米至数百米, 而宜昌到宜宾江段, 窄的峡谷只有 100 多 $\mathrm{m}$, 宽的江段近 $2000 \mathrm{~m}$. 中下游河段逐渐宽阔,一般有近千米, 河口处可达数千米之宽. 因此,粗略地 估算, 长江干流的水面面积应该小于两湖 (洞庭湖和鄱阳湖) 现有面积之和. 但是长江干流的饵料生物丰度 (单位面积) 大概充其量只有两湖的 $1 / 7^{[9]}$,因此,干流对物种的承载力是十分有限的. 


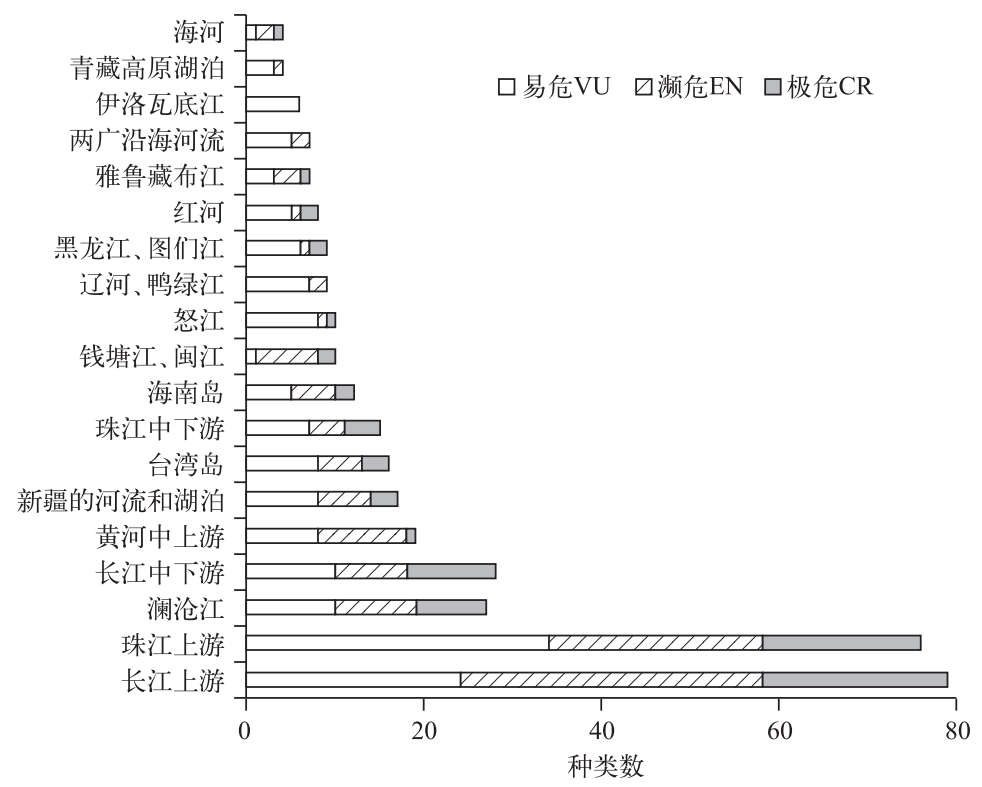

图 2 中国内陆鱼类受威胁物种的地理分布 (钱塘江、闽江包含福建和浙江两省独立人海河流; 青藏高原湖泊 指西藏和青海两省的封闭湖泊;两广沿海河流指广东和广西所有沿海独立人海的河流) (引自文献 [25])

Fig.2 Distribution of threatened species of Chinese continental fish ( Qiantangjiang River and Minjiang River include all coastal rivers in both Fujian and Zhejiang Provinces; Lakes of Qinghai-Tibet Plateau include all plateau inlet lakes in Tibet and Qinghai Provinces; Coastal Rivers of Guangdong and Guangxi are all coastal rivers independently flowing into South China Sea (cited from reference[25])

\section{5 漂流性卵一一游刃有余}

葛洲坝和三峡大坝对产漂流性卵鱼类一一四大家鱼的影响甚微, 对这些物种的生存来说, 可谓毫发未 损. 四大家鱼资源量在中下游干流中的衰退, 与葛洲坝和三峡大坝并无关系, 而主要是由于江湖阻隔引起 的, 因干流中饵料贫㾑, 而它们又无法到湖泊中去肥育.

四大家鱼产卵场的分布范围十分广阔, 在葛洲坝修建之前, 在长江干流四川巴县至江西彭泽长达 1700 $\mathrm{km}$ 江段上,具有一定规模的产卵场有 36 个之多. 在葛洲坝截流之后的 1981 年的调查发现,在重庆到武穴的 $1520 \mathrm{~km}$ 江段内, 共监测到四大家鱼产卵场 24 处, 在宜昌以上江段中, 除过去调查所发现的产卵场全部存在 外, 还新发现高家镇和奉节两个产卵场 ${ }^{[26-27]}$. 在三峡大坝修建后的 2005-2007 年的调查发现, 对产卵场的 影响主要在库区,即在三峡库区的四大家鱼产卵场消失,但在三峡库尾的江津以上江段以上却形成了新的 产卵场, 位于合江一弥陀江段, 也就是说原库区江段产卵场上移了 ${ }^{[28-30]}$. 三峡大坝截流后, 局部江段四大家 鱼苗的减少 (如监利江段 ${ }^{[31]}$ ) 并不一定意味整体情况就是如此, 也许是因为水文形势的变化改变了原有产 卵场的分布格局. 总体上来看, 葛洲坝和三峡大坝对四大家鱼繁殖的影响微乎其微.

此外, 四大家鱼的自然分布十分广泛,鲢分布于红河与黑龙江之间,鲜分布于珠江与黄河以北的海河之 间,青鱼和草鱼分布于珠江与黑龙江之间,这些物种本身不存在任何灭绝的风险.

此外, 自中世纪以来, 四大家鱼特别是鲢、鳙被引种到许多国家或地区, 据统计, 鲢被引种到 71 个国家, 鳙被引种到 51 个国家 ${ }^{[32]}$. 现在鲢、鳙在美国的几大主要河流已泛滥成灾,生长状态极佳, 并威胁到五大湖的 土著鱼类, 可能原因与饵料 (浮游动植物) 丰富、缺乏天敌及美国人不爱食用有关. 据说美国政府决定斥资 180 亿美元对其进行控制.

长江中的鮯鱼是一种大型凶猛鱼类, 是原始雅罗鱼亚科鱼类适应掠食大型鱼类而特化出的一个分支, 
对维持长江鱼类群落结构的平衡起到过重要作用 ${ }^{[33]}$. 美国河流中也有一种大型凶猛鱼类一一鳄雀鳝 (Atractosteus spatula), 它是北美第二大淡水鱼,被誉为十大最凶猛的淡水鱼之一. 鳄雀鳝现在主要分布在美国南 部, 曾经在其分布北限的范围内数量也很多, 但由于栖息地破坏、无辜滥杀、过度捕捞等,在这些曾经的分布 区现在已难受踪影, 因此,美国人正试图将鳄雀鳒重新引人位于田纳西和伊利诺斯之间的河流中, 以控制人 侵的四大家鱼 ${ }^{[34]}$.

而在长江中下游干流中, 四大家鱼的资源量却迅速衰退, 因在长江干流中, 食物极为匮乏, 但这种衰退 通过食物链影响顶级消费者 (如白㟲豚和江豚) 的威胁远大于四大家鱼自身的物种维持问题.

\section{6 物种灭绝一子遗当先}

子遗物种容易灭绝. 子遗物种, 也称为古特有种、残遗种或活化石, 大概都是指一些曾经从主要的灭绝 事件中幸存下来并保留了过去原始特性的种类或类群,或者指一些在历史时期曾分布广泛但之后大量灭绝 现仅残存于局部区域的物种或类群.

\section{1 豚的哀嚎——饥饿与误杀}

鲸绝大部分生活在海洋中, 只有几种淡水豚类, 它们可能是在中新世中期偶然地适应了河流栖息地环 境而幸运地保存下来, 是子遗物种 ${ }^{[35]}$. 但是, 鲸体型太大, 并不适应较小的淡水环境, 在淡水中幸存下来的 也仅限于世界上的少数大河.

白暨豚和江豚都是以长江或湖泊中的鱼类为食 ${ }^{[36-39]}$. 饥饿与捕捞误杀使白暨豚灭绝以及江豚濒危. $1950 \mathrm{~s}$ 以来, 长江干流的渔业资源量下降了 $81 \%$ ( 从 $4.3 \times 10^{5} \mathrm{t}$ 减少至 $8.0 \times 10^{4} \mathrm{t}$ ), 这给依赖于这些饵料生活 的高营养级动物一一白暨豚和江豚带来了不可估量的影响. 1950s 中后期开始的江湖阻隔是干流渔业资源 下降的主要原因. 河湖关系的改变阻止了湖泊渔业资源对长江干流的补充, 而浑浊的干流自身其生态支撑 功能极为有限. 酷渔滥捕也加速了干流渔业资源的衰退, 其对豚类的误杀在可统计的人为致死因素中也高 居榜首 ${ }^{[40]}$, 如根据 1955-1984 年期间白暨豚的死亡统计, 渔用滚钩致死的比例高达 $48 \%$, 很多江豚亦被滚

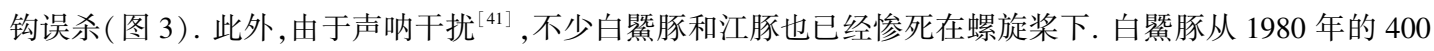
头左右下降到 20 世纪末的不足 50 头, 2006 年再没有发现任何个体 ${ }^{\left[{ }^{[37,42-48]}\right.}$. 1984-1991 年期间, 长江中下游 江豚种群数量约为 2700 头, 2006 年下降到 1800 头左右, 2012 年仅有约 1040 头 ${ }^{[47,49]}$. 白鴊豚在三峡截流之 前就基本绝迹, 因此, 其绝灭与三峡工程的影响应该没什么关系.

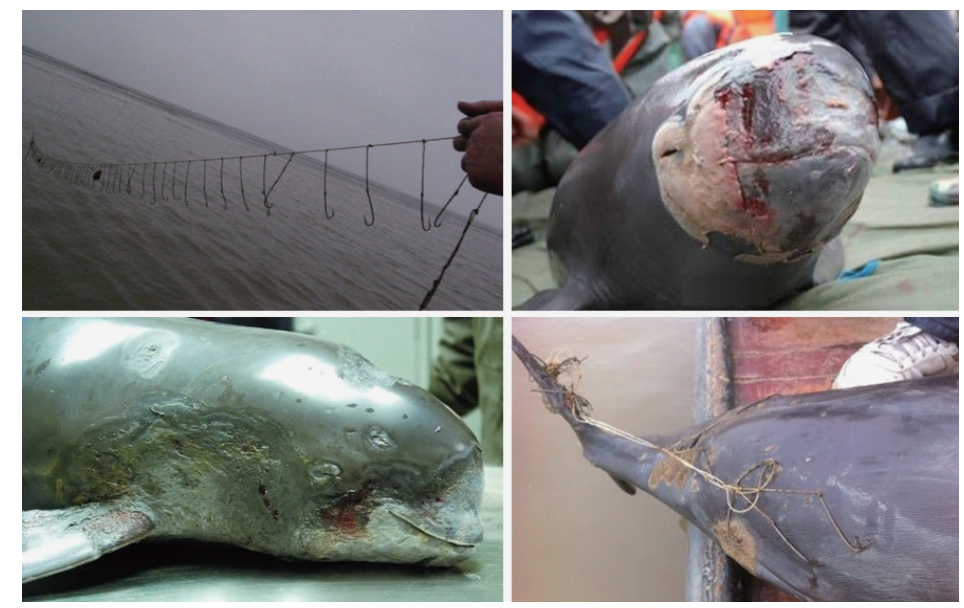

图 3 洞庭湖中被滚钩误杀的江豚

Fig.3 Killed individuals of finless porpoise by fishing jig in Lake Dongting

伴随饵料资源量的大幅下降, 依赖它们的捕食者一白箩豚和江豚的种群规模出现类似比例的下降不 足为奇, 可能本来白頭豚就更为稀少一些, 再加上体型更大, 繁殖力更低, 只限于在淡水中生活, 且更依赖于 
声呐与外界联系, 白箽豚率先灭绝合乎情理. 像白殿豚和江豚这样的哺乳动物, 对上游并无多少依赖性, 但 中下游饵料生物资源的剧减, 使其种群难以为继, 加上捕捞误杀以及螺旋桨致死等, 白暨豚几乎灭绝, 江豚 也危在旦夕.

\section{2 鲟道被断——葛洲坝难辞其各}

鲟鱼是古老的冷水性鱼类,譬如在长江中的中华鲟可能就是在冰期由北方向南方扩散而来. 鲟类是介 于软骨与硬骨之间的古老鱼类, 可能起源于 $2.45 ~ 2.08$ 亿年前的三叠纪, 因此也有 “活化石” 之称 ${ }^{[50]}$. 中华鲟 和白鲄体型巨大, 活动空间大, 需要到长江上游的金沙江去产卵, 特别是中华鲟还要到海洋中摄食 (主要食 物为底栖动物和小杂鱼) 与生长 $8 \sim 14$ 年 ${ }^{[51-52]}$, 白鲟也需要大的生存空间, 需要到中下游去摄食与生长, 暮洲 坝的修建就注定了这两种鲟鱼的灭绝之运. 分布于中上游且体型较小的达氏鲟 (A. dabryanus) 虽然情况略 好, 但未来亦不容乐观. 尽管中华鲟和白鲟热爱它们的金沙江, 充满着对急流与砾石的渴望, 以及对饥饿和 遥远里程的䅐视, 它们终究越不过人类建造的大坝.

中华鲟和白鲟由于葛洲坝的修建而失去了独特的产卵场, 现濒临灭绝. 中华鲟从大海来到长江, 忍饥挨 饿 1 年多, 长途跋涉数千公里到达长江上游的金沙江, 那里有湍湍急流, 河底有砾石, 亲鱼将它们的卵黏附 于砥石或掉落于砾石㖓隙之中, 之后亲鱼以及孵出的仔鱼再游向大海, 仔鱼要在大海中摄食生长 $8 \sim 14$ 年, 待成熟时方游向金沙江去产卵, 产卵场的范围也相对狭窄 (与产漂流性卵的四大家鱼相比). 1980s 初, 葛洲 坝的建成使性成熟的中华鲟无法上溯到原先的产卵场, 一些亲鱼向坝上硬闯, 撞得头破血流伤重而亡, 另一 些则性腺退化重返大海 ${ }^{[53]}$. 在葛洲坝上游留存的少数亲鱼即使产卵也回不到大海, 先后饿死. 1970s 长江中 的中华鲄繁殖群体尚有 1 万余尾, 1983-1984 年下降到约 2176 尾, 2005-2007 年期间下降到了 203 257 尾, 到了 2010 年只剩数十尾.

人们曾期待在葛洲坝下会形成新的产卵场 ${ }^{[54-55]}$, 再现适宜于中华鲟产卵的同样的水文与底质条件, 刚 开始, 确实给人带来过一丝惊喜, 但在坝下所形成的新产卵场其规模小得可怜 ${ }^{[33]}$ (图 4), 根本难以扭转中华 鲟衰亡的厄运, 中华鲟的种群数量依然在快速衰退. 三峡大坝蓄水之后, 中华鲟有停止产卵的现象 ${ }^{[56]}$, 有人 认为是三峡大坝改变了坝下产卵场的温度,使产卵时间推迟,但问题是, 推迟也应该产啊. 我更愿意相信, 当 亲鱼的种群密度低到一定程度时, 在坝下产卵场见不到亲鱼产卵也不足为奇.

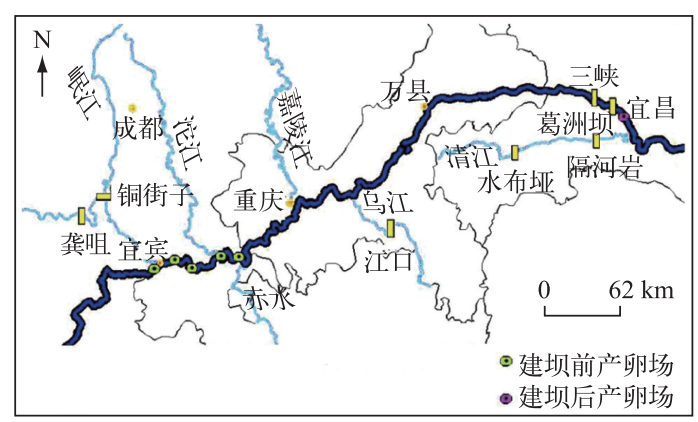

图 4 葛洲坝修建前后中华鲟产卵场的变化(修改自文献[57])

Fig.4 Changes of spawning sites of Chinese sturgeon before and after the construction of Gezhouba Dam ( revised from reference $[57]$ )

中华鲄的产卵场在上游但又必须回到海洋中去摄食与生长, 当葛洲坝建成后, 它的灭绝就已经注定 ${ }^{[58]}$, 三峡大坝最多只是完成了最后一击.

中国最大的淡水鱼一一白鲟的命运与中华鲟十分类似, 它的体型大, 活动空间也大, 虽然它对大海的依 赖性没有中华鲟那样强烈,但其活动空间也涵盖了中下游和邻近海域. 它在长江中以鱼为生,每年春季上溯 到四川省泸州以上江段产卵,集中于江安县附近的长江河段和宜宾柏树溪附近的金沙江河段,那里水流较 急, 底质多为岩石或鹅卵石 ${ }^{[9,59-60]}$. 白鲟显然无法在葛洲坝上江段中平安地生存, 无法忍受生存空间被如此 大范围地压缩, 在葛洲坝下也没有发现新的产卵场 ${ }^{[55]}$. 现在, 白鲟已难受踪影. 
达氏鲟属淡水定居型鲟种, 主要以底栖无脊椎动物为食, 体型比中华鲟和白鲟要小得多, 活动范围也主 要在中上游 ${ }^{[7,53]}$, 性成熟个体上溯至长江上游的重庆至宜宾江段繁殖, 卵黏着在石砾滩底上发育 ${ }^{[61]}$. 达氏鲟 比中华鲟和白鲟的生存状态要略好一些,但也是处于极危状态.

总的来看, 在上游水流湍急的石砾滩底上产粘性卵的大型鱼类( 如中华鲟、白鲟、达氏鲟、胭脂鱼 (Myxocyprinus asiaticus) 等) 其产卵场具有不可替代性, 似乎难以在葛洲坝下形成或形成足够规模的新产卵场, 可 能没有或没有足够规模的砾石底质能满足卵附着等方面的需求. 这些鱼自葛洲坝建成以来就开启了绝灭 之旅.

\section{3 其它子遗物种}

鮏也是冷水性鱼类, 体型一般也较大, 它们多是在海洋中肥育, 但成熟后都需要在淡水中繁殖, 只有少 数陆封型种类 (这也表明它们并不太适应纯淡水的生活). 因此, 鲑一般需要很大的活动空间. 在长江上游分 布的川陕哲罗鲑 (Hucho bleekeri) 和秦岭细鳞鲑 (Brachymystax lenok tsinlingensis) 是海产遗留种 ${ }^{[62]}$, 成鱼均主 要以鱼类为食 ${ }^{[63]}$, 它们是冰期自北方南移的冷水性残留种, 冰期结束后, 它们选择了停留在海拔较高、水温 较低的河流中, 并生存了下来, 成为了陆封型物种. 虽然它们能够完全在淡水中生活, 但它们的生存空间有 限, 容易被人类活动所压缩 ${ }^{[64-65]}$, 乃至走上灭绝之道. 川陕哲罗鲑 (Hucho bleekeri) 在 1960 年以前数量较多, 是产区的一种大型经济鱼类, 最大个体可达 $50 \mathrm{~kg}$, 仅 1971 年玛柯河地区的捕获量就在 $2500 \mathrm{~kg}$ 以上, 但目 前在四川、陕西境内已经绝迹,青海省玛柯河成为其唯一分布水域,数量极为稀少 ${ }^{[66]}$.

亚口鱼科鱼类绝大部分都生活在美洲, 仅 1 种 (胭脂鱼) 生活在长江, 表明亚洲并不是它们的宜居之地, 据说历史上从非洲扩散而来的胭脂鱼在亚洲大部分已经灭绝了. 因此,长江的胭脂鱼也是一种残留种. 胭脂 鱼主要以底栖无脊椎动物为食, 亦需要上溯到长江上游的金沙江等河段中产卵, 之后需回到中下游去生 活 ${ }^{[9]}$. 与鲟鱼一样, 葛洲坝的建成就切断了它的生殖洄游通道, 在坝下虽形成了新的产卵场, 也阻挡不了野 生种群不断下降的趋势. 胭脂鱼曾是长江上游的重要经济鱼类之一, 据 1958 年宜宾市渔业社的统计, 在怅 江的渔获物中, 胭脂鱼占总产量的 $13 \%{ }^{[9]}$, 但到 1970s 葛洲坝水利枢纽建成以前, 胭脂鱼资源量就已明显减 少, 1970s 中期已降至 $2 \%{ }^{[60]}$, 葛洲坝截流后, 上游的胭脂鱼几近绝迹.

鲱形目鱼类也是古老而原始的真骨鱼类, $90 \%$ 以上都生活在海洋, 因此, 淡水并不是它们适宜的生存之 地. 鲋是一种洄游性鱼类, 主要以浮游生物为食, 虽不能上溯到长江上游去产卵, 但亦在鄱阳湖上游的河道 中产卵 ${ }^{[9,67]}$. 赣江平流梯级枢纽工程的兴建, 阻断了鲋鱼的产卵洄游路线, 加上经济价值高, 人们对其疯狂 捕捞, 这些导致了鲋鱼种群数量的急剧下降. 长江鲥鱼的产量在 1960s 约为 $309 \sim 584 \mathrm{t}, 1980 \mathrm{~s}$ 产量下降到 $12 \sim 192 \mathrm{t}, 1986$ 年仅 $12 \mathrm{t}$, 已不能形成鱼汛 ${ }^{[67]}$.

除了鲋以外,上述濒危动物都是大型种类,都需要巨大的生存空间来完成生活史,生境的片段化往往给 它们带来灭顶之灾. 这些水中的巨无霸纷纷走上灭绝之道, 演绎与很多大型陆生哺乳动物相似的命运. 它们 在进化上过于复杂, 牺牲了对生存环境波动 (特别是强烈人类活动干预) 的可塑性, 容易走向绝灭之道 ${ }^{[68]}$.

\section{7 即将失守的最后阵地一一洞庭湖和鄱阳湖}

长江多年 $\left(1951-1983\right.$ 年) 平均实测年径流量 $8.956 \times 10^{11} \mathrm{~m}^{3[69]}$, 约占全国总径流量的 $37.7 \%$. 位于长江中 游的洞庭湖和鄱阳湖是我国最大的两个淡水湖, 其容积十分巨大一一洞庭湖 $1.670 \times 10^{10} \mathrm{~m}^{3}$, 鄱阳湖 $1.496 \times 10^{10}$ $\mathrm{m}^{3}$, 多年平均径流量分别为 $3.126 \times 10^{11} \mathrm{~m}^{3}$ 和 $1.460 \times 10^{11} \mathrm{~m}^{3[70]}$, 占长江年径流量的 $52 \%$. 根据 1953-2012 年 的统计资料,洞庭湖四口多年平均径流量为 $8.730 \times 10^{10} \mathrm{~m}^{3}$, 占洞庭湖总径流量的 $30.8 \%{ }^{[71]}$. 三峡大坝运行前 (1990-2002 年), 鄱阳湖平均倒灌 $5.15 \mathrm{~d}$, 倒灌量 $1.283 \times 10^{9} \mathrm{~m}^{3}$; 三峡蓄水初期 (2003-2008 年), 平均倒灌 $15.83 \mathrm{~d}$, 倒灌量 $3.591 \times 10^{9} \mathrm{~m}^{3}$, 三峡水库 $175 \mathrm{~m}$ 试验性蓄水 (2009 年) 以来, 平均倒灌至 $2.14 \mathrm{~d}$, 倒灌量仅 $1.460 \times 10^{8} \mathrm{~m}^{3[72]}$. 因此, 从与长江的生态联系来看, 像四大家鱼这些产漂流性卵鱼类的幼鱼现在已很难在洪 水季节进入鄱阳湖, 从这种意义上来说, 对长江干流渔业资源的影响可谓雪上加霜.

两湖曾经都是我国特有的淡水豚类一一白暨豚的故乡,白暨豚的模式标本还采自洞庭湖 ${ }^{[73]}$, 也是江豚 的重要栖息之地. 中国科学院水生生物研究所等部门对洞庭湖和鄱阳湖的江豚进行了多轮的现场考察, 1990s 以来, 两湖中的江豚数量在 $85 \sim 200$ 头范围内波动 ${ }^{[49,74-75]}$, 表明三峡截流并未引起两湖中江豚数量的 
明显降低.

1950s 以来,洞庭湖的鱼产量并未呈现系统性的衰退现象, 虽然湖泊面积由所下降 (1958 年 $3141 \mathrm{~km}^{2}$ 减 少至 1995 年 $2625 \mathrm{~km}^{2}$ ). 除 1996、1998 年溃垸因素, 捕捞量较高外, 洞庭湖鱼类捕捞量绝大多数情况下在 $2 \times$ $10^{4} \sim 4 \times 10^{4} \mathrm{t}$ 之间徘徊, 多年平均约为 $3.3 \times 10^{4} \mathrm{t}$ (图 5). 与洞庭湖类似, 鄱阳湖的鱼产量也在 $2 \times 10^{4} \sim 4 \times 10^{4} \mathrm{t}$ 之间徘徊, 而且 $1990 \mathrm{~s}$ 之后比 $1950 \mathrm{~s}-1980 \mathrm{~s}$ 更高 (图 6). 这与长江干流的资源量从 1954 年的 $4.3 \times 10^{5} \mathrm{t}$ 下降 到 2011 年的 $8.0 \times 10^{4} \mathrm{t}$ 有着天壤之别 (图 7). 同样都是酷渔乱捕, 为何两湖与长江干流渔业资源的走势如此 天壤之别呢? 依笔者之见,这恰好说明,酷渔乱捕可能不是长江干流渔业资源衰退的主因.

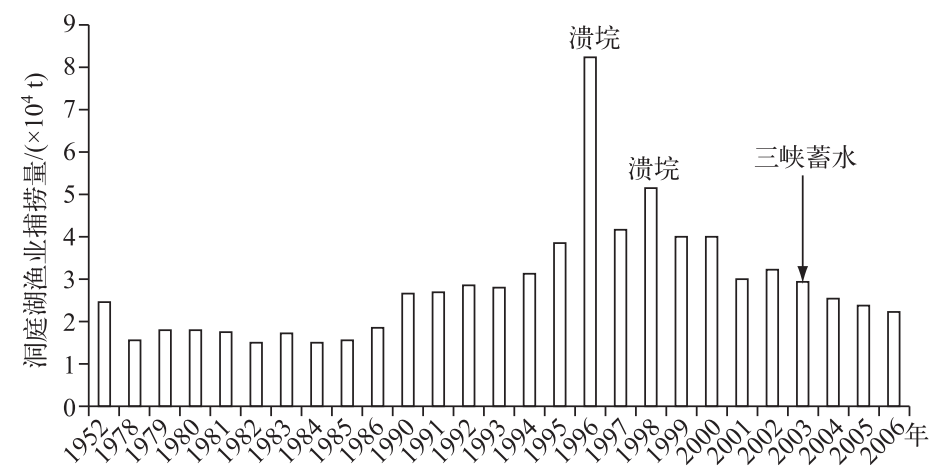

图 5 洞庭湖渔业捕捞量的历史变化 (根据湖南水产部门的统计数据绘制而成 ${ }^{[76-78]}$ )

Fig.5 Historical changes in total fishery catch in Lake Dongting ( data from statistics by the Hunan Fisheries Division ${ }^{[76-78]}$ )

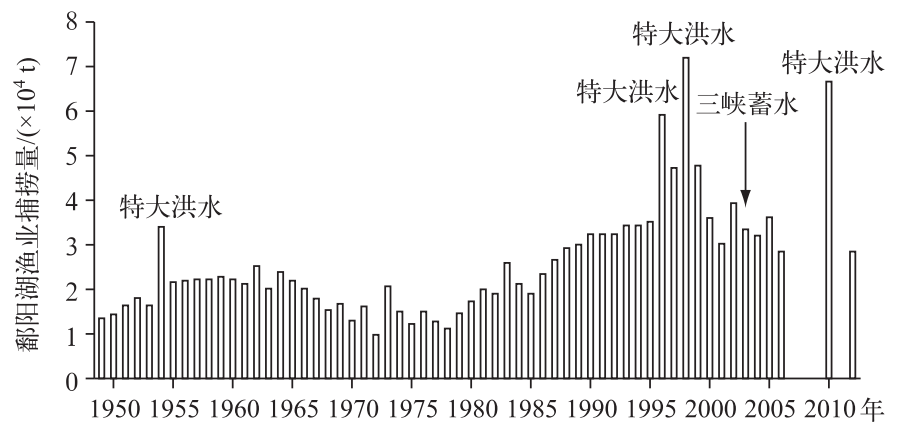

图 6 鄱阳湖渔业捕捞量的历史变化 (根据江西省渔政管理局的数据绘制而成 ${ }^{[79-81]}$ )

Fig.6 Historical changes in total fishery catch in Lake Poyang (data from statistics by Fishery Administration Bureau of Jiangxi Province ${ }^{[79-81]}$ )

自 2003 年起,农业部在长江干流、一级通江支流和鄱阳湖区、洞庭湖区分段实施了春季 (4-6 月) 禁渔 制度, 并开展增殖放流活动, 最近有学者建议在长江休渔十年, 这些都值得赞赏, 但这可能还无法迅速扭转 局面, 因为过度捕捞并不一定是长江鱼类资源大幅衰退的主因, 因此, 即便是在长江干流休渔十年, 未必能 够恢复长江干流的鱼类资源量, 因为 1950s 以来的江湖阻隔使支撑长江鱼类的有效湖泊面积减少了 $76 \%$, 而 干流的覀料稀少.

洞庭湖和鄱阳湖是目前在长江中下游仅存的与干流保持联系的自然湖泊, 虽然它们仅占 20 世纪中叶 长江中下游湖泊总面积的 $24 \%$, 但对现在干流渔业资源的维持依然起着十分重要的作用, 它们如果被阻隔 开来 (图 8), 长江干流的渔业资源将进一步衰退, 可能会引发新一轮的链式灭绝效应. 虽然鄱阳湖湖控工程 提出了 “建闸不建坝, 调枯不控洪, 拦水不发电, 建管不调度, 江湖两利, 动态调控” 的口号, 并承诺汛期 4-8 


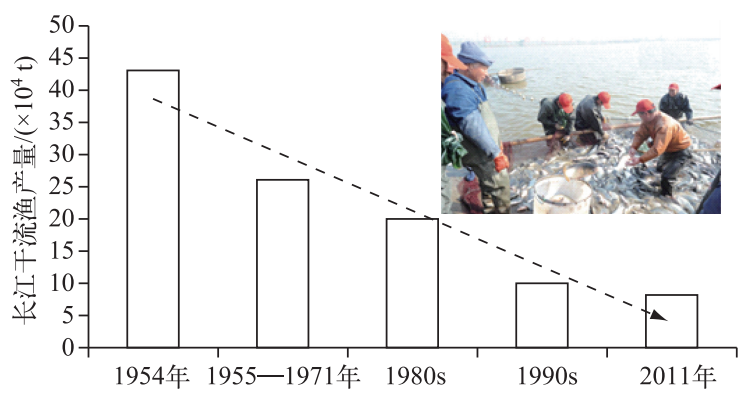

图 7 长江干流渔业捕捞量的变化

Fig.7 Changes in total fishery catch of the Yangtze River

月闸门全开, 江湖连通, 只是在汛末对湖区水位进行节制, 缓解湖区水位下降过快导致的问题. 依笔者之见, 这只是考虑了鄱阳湖对水的截留,但问题是无论如何调控, 必定会改变原有的江湖关系和水文节律 (虽然有 一定的波动性), 江水倒灌不可能改善, 而只会更加困难. 事实上, 2009 年以后每年平均就只有 $2 \mathrm{~d}$ 的倒 灌 ${ }^{[72]}$, 湖控工程的实施可能使倒灌彻底消失, 鄱阳湖对长江干流渔业资源的补给作用可能因此而进一步 削弱.

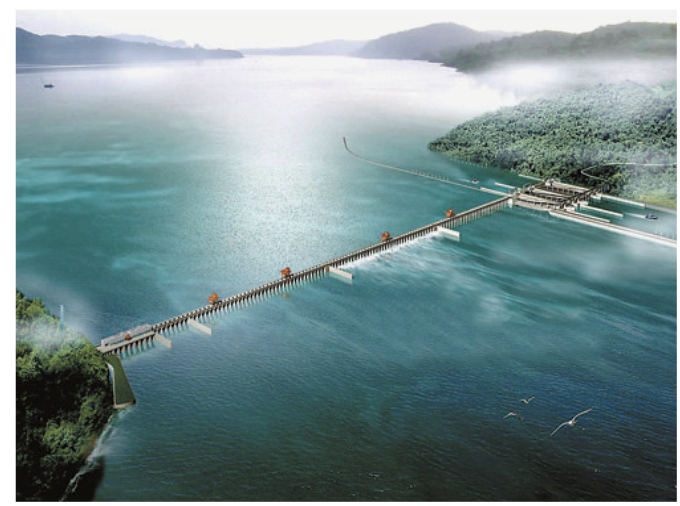

图 8 拟建的鄱阳湖水利枢纽效果图

Fig. 8 The proposed water control project in Lake Poyang

陈家宽等 ${ }^{[82]}$ 批评道: “用工程措施解决问题, 无异于头痛医脚, 并将造成不可预计的生态风险. 修建鄱 阳湖水利枢纽工程的必要性在哪里? 究竟是“为”生态, 还是 “伪”生态”? 在笔者看来, 这可能是一种负薪 救火的方法! 正如利奥波德 ${ }^{[83]}$ 所言: “我们的自大和完美的社会, 现在就像一个忧郁病患者, 它是那样为其 自身的经济健康而困扰着, 结果反而失去了保护其健康的能力”.

湖南省也正式提出了在东洞庭湖的出口河段 (君山至城陵矶) 建设岳阳综合枢纽工程的方案 (图 9), 其 理由也是因为三峡工程使洞庭湖枯水期提前以及枯水位下降等带来的问题, 如果该工程实施, 洞庭湖的面 积将从现在的 $2600 \mathrm{~km}^{2}$ 增加到 $4100 \mathrm{~km}^{2}$, 总装机容量 $2.0 \times 10^{5} \mathrm{~kW}$, 年枯水期发电量 $4.8 \times 10^{8} \mathrm{~kW} \cdot \mathrm{h}$. 这居然 被称之为洞庭湖生态建设的 “龙头工程”. 以笔者之见, 洞庭湖枢纽比鄱阳湖枢纽的生态危害更大, 不仅因为 它的强控制性, 而且因为洞庭湖对长江生物多样性的支撑比鄱阳湖更为重要. 如果两湖相继建闸, 江豚将失 去两个最重要的栖息之地,将很快灭绝.

\section{8 灭绝一一无法阻挡?}

\section{1 王牌纷纷倒下}

从历史起源和生态学的双重视角来看, 以水利工程为主的人类活动对长江水系的生物多样性产生了显 


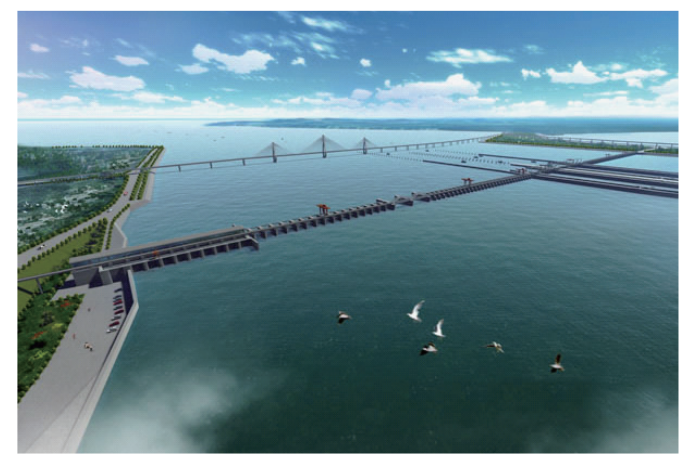

图 9 拟建的岳阳综合枢纽工程效果图

Fig.9 The proposed water control project in Lake Dongting

著的负面影响, 通过累积的方式使这种负面效应得到了致命的显现. 特别是,一些子遗物种的生态位被压 缩, 或生态廊道 (如繁殖洄游通道) 被阻断, 它们完成生活史所需的时空完整性以及生态过程完整性受到了 损伤, 长江水系的生物多样性总体承载力明显下降.

旗舰物种一一白暨豚已经功能性灭绝,已经不可能有任何复活的幺想. 旗舰物种一一江豚也处在灭绝 的边缘, 因为长江中下游由于江湖阻隔导致其适口的饵料资源过于稀少, 过度捕捞更是雪上加霜, 虽然迁地 保护也许能阻止其快速灭绝, 但由于中下游干流的渔业资源不可能有根本改观 (除非大量拆除导致江湖隔 离的节制闸), 因此, 江豚的前景不容乐观. 如果江豚真的仅限于淡水生活, 它们的灭绝可能也只是时间的早 晚问题. 旗舰物种一一华鲟和白鲄的灭绝已不可避免, 因为它们的产卵场已无法在坝下有效复制, 葛洲坝 和三峡大坝也不可能拆除, 而通过人工的方式来完成其生活史也不大可能. 胭脂鱼因为个体相对较小, 人工 饲养也比中华鲟和白鲟容易, 人工繁殖也比较容易,因此比鲟鱼的前景相对乐观.

\section{2 水坝是祸首,酷捕是帮凶}

水利工程对长江干支流豚类和一些珍稀濒危鱼类生存的打击是毁灭性的, 1950s 开始的江湖交汇处节 制闸的建设 (加上酷渔滥捕) 导致了白塈豚和江豚的衰亡, 暮洲坝的建设导致了 3 种鲟鱼、胭脂鱼的衰亡 (三 峡大坝只是起到了雪上加霜的作用), 上游水电建设加上酷渔滥捕导致了冰期遗留种——虎嘉鲑 (Hucho bleekeri) 和秦岭细鳞鲑逐渐走向衰亡.

长江流域的特有鱼类主要分布在上游水系, 它们基本都是适应激流环境的种类,有些还要进行迁徙 (或 长或短), 已建成的数以万计的水电站对许多鱼类栖息的水文情势带来了不可逆转的巨大改变,阻断了不少 鱼类的迁徙通道,很多鱼类的栖息地被片段化,生存空间被大大压缩.

酷渔乱捕对物种濒危的影响有些是直接的, 有些是间接的. 几乎所有濒危物种都曾是人类猎杀的对象, 有些后来虽然被禁止猎杀, 但也免不了被误杀, 譬如, 中华鲟虽然已十分稀少, 但还是时常被渔民误捕, 要是 被网误捕, 抢救及时或许能救上一命, 如果是滚钩, 就必死无疑了. 在长江以及两湖中酷渔乱捕现象严重, 导 致鱼类资源小型化 (群落结构低龄化), 这使得产漂流性卵的大型鱼类的资源不断衰竭, 而在干流中这意味 着豚类等的适口饵料大幅减少了.

\section{3 为什么保护?}

我们人类从生态系统中获得各种惠益, 但如果我们盲目追求眼前效益, 就会使得生态系统服务的持续 供给能力受到损害 ${ }^{[84]}$. 人类的短视和贪婪总是导致对资源的过度开发和消耗 ${ }^{[85]}$. 为了享受, 他必须拥有、侵 犯、占用 ${ }^{[83]}$. 欲望使我们对长江进行疯狂的肢解与掠夺, 但长江是一条生命之河, 它的活力来自于干流、支 流、湖泊和湿地的血脉沟通形成的独特生命系统 ${ }^{[86]}$.

世界各国正在采取一致行为以共同应对日益严重的全球性生物多样性危机. 1992 年,在巴西里约热内 卢举行的联合国环境与发展大会上签署了《生物多样性公约》、《里约宣言》, 在所发布的《地球宪章》中指 出, “地球提供了生命演化所必需的条件, 生命群落的恢复力和人类的福祉依赖于: 保护一个拥有所有生态 
系统、种类繁多的动植物、肥沃的土壤、纯净的水和清洁的空气的健全的生物圈. 资源有限的全球环境是全 人类共同关心的问题. 保护地球的生命力、多样性和美丽是一种神圣的职责” ${ }^{[87]}$. 《生物多样性公约》于 1993 年 12 月 29 日正式生效, 目前共有 196 个缔约方, 中国是最早的缔约方之一. 该公约具有法律约束力, 旨在保护濒临灭绝的动植物和地球上多种多样的生物资源.

对生物多样性的保护依赖于我们的自然价值观, 而侠义或极端的以人为本主义助长了人类对自然资源 的肆意掠夺与猎杀. 人们很早就开始探索自然保护的伦理问题. 美国保护生物学家缪尔 (John Muir, 18381914 年) 认为, 自然的内在精神价值要高于其可以触摸的物质价值, 提出了自然内禀价值 (intrinsic value) 的 概念, 强调无人类干预的纯自然保护. 美国林务局首任局长平肖 (Gifford Pinchot, 1865-1946 年) 认为, 自然 资源的适度利用就是在最长的时间内让最多的人获得最大的利益, 资源应当在个体间以及当代和后代间公 平分配. 美国生态学家利奥波德 (Aldo Leopold, 1887-1948 年) 提出保护的目标是维护自然生态系统和生态 过程的健康, 是人与自然的和谐状态, 并成功地说服政府建立原野保护地, 他认为人类是生态系统的一部 分, 而不仅仅是自然资源的利用者 ${ }^{[88]}$. 我很欣赏利奥波德的一段名言: “野生的东西在开始被摒弃之前, 一 直和风吹日落一样, 被认为是极其平常而自然的. 现在我们所面临的问题是: 一种平静的较高的 “生活水 准, 是否以值得牺牲自然的、野外的和无拘束的东西为代价. 对我们这些少数人来说, 能有机会看到大雁比 看电视更重要, 能有机会看到一朵白头翁花就如同自由谈话的权利一样, 是一种不可剥夺的权利” ${ }^{[83]}$.

\section{4 如何保护?}

保护与开发永远都是一对矛盾. 一方面, 以长江黄金水道为依托的长江经济带建设如火如茶, 这毫无疑 问将使长江的生物多样性维持与水环境保护面临空前的压力, 另一方面, 自然保护的力度也在加大, 如在长 江流域已有国际重要湿地 18 处,湿地自然保护区 167 处, 国家湿地公园 291 处 $^{[89]}$. 在长江中下游还有江豚 自然保护区 4 个,白䈍豚自然保护区 2 个,中华鲟自然保护区 2 个,四大家鱼国家级种质资源保护区 4 个; 在 上游还有水生野生动物自然保护区 12 个, 国家级水产种质资源保护区 23 个. 保护与开发的激烈交锋还将 持续.

我们需要从历史的视角分析现在的危机, 因为, 现代长江水系的生物多样性格局不是与生俱来的, 而是 演化的产物. 亚热带季风气候是长江水系独特生物区系的基础, 而东亚季风气候又是青藏高原隆升 (由印度 板块与欧亚大陆板块碰撞所引起) 的结果, 至少它使季风加强了, 随之三峡河段贯通, 古长江改道东流, 这些 重大气候与地质事件, 是长江生物多样性起源与演化的重要基础, 从中可以窥视鱼类区系的特有性以及它 们的生态需求, 以及物种的多样性是如何维持的. 只有知道了物种多样性的历史成因, 才容易理解人类活动 为何导致了水系中生物多样性的大量丧失. 我们需要了解各个物种完成生活史所需的时空 (如江湖连通性) 连续性以及生态过程 (如水文过程、温度过程) 的完整性. 准确预警物种的濒危其实十分困难, 拯救就更不用 说. 我们的最终目的就是要对受损的生态系统进行修复或再自然化, 虽然这在大江大河中基本是不可能的, 但这样的努力依然值得, 因为这至少可以延缓或逆转一些水生动物的衰退或濒危趋势.

能否扭转现在的颓势, 不可轻易乐观. 长江是一个巨大的生态系统, 它的全长达 $6300 \mathrm{~km}$, 流域面积 180 万 $\mathrm{km}^{2}$, 占全国总面积的 $18.7 \%$. 事实证明, 目前我们根本就不知道怎样对长江水系这样一个巨大而复杂的 生态系统进行科学管理, 才导致了今天这样的后果. 生态系统管理的思想虽然可追溯至 1930s, 但直到 1980s 才提出了理论框架 ${ }^{[00]}$. Ludwig 等 ${ }^{[85]}$ 认为, 依据科学数据对生态系统的管理必然要受到自然过程的大尺度、 高度的自然变异性、复杂的生态系统和人类行为所固有的不可预测性所制约. 对长江水系的生态系统管理 来说, 莫不就是如此.

\section{5 杯水车薪一人工放流、生态调度、保护区与十年禁捕}

人们曾对人工放流寄予厚望. 为了拯救中华鲟, 从 1984 年起就开始向长江内放流人工繁殖的中华鲟幼 苗,据估计,在 1984-2005 年间,已累计放流中华鲟幼苗 453 万余尾; 自 2005 年起, 由中国水产科学研究院 长江水产研究所、葛洲坝集团中华鲟研究所、湖北恒升实业有限公司、江苏省昆山市东方特种水产有限公司 和上海市长江口中华鲟自然保护区管理处 5 家单位共同承担了中华鲟的人工繁殖放流工作, 每年继续向长 江投放 10 万尾以上的中华鲟幼苗 ${ }^{[31]}$. 但问题是, 这并未能阻挡住中华鲟灭绝的步伐. 既然无可挽救, 是谁 以及根据什么做出了这样重大的决策? 中华鲟的人工放流可能难逃彻底失败的命运, 但我们至少得知道为 
何失败了吧. 也许中华鲟根本就是一个救不了的物种 (可能因为它的体型太大, 寿命太长, 生活史太复杂, 对 产卵场的要求太苛刻, 对环境的可塑性太弱……), 我们从一开始就必须选择放弃, 既然我们选择了大坝.

除了以物种保护为目的的人工放流外, 还有以资源增殖为目的的人工放流. 2003 年开始, 长江流域云 南、四川、贵州、重庆、湖北、湖南、江西、安徽、江苏、上海十个省市陆续开展了鲢、草、鳙、青鱼的人工繁殖放 流工作, 2005-2007 年 3 年间, 累计放流 10 万余尾 ${ }^{[31]}$. 这个放流数量简直少得令人笑话, 因为 $1960 \mathrm{~s}$, 整个 长江干流四大家鱼年产卵规模高达 1000 1300 亿, 1981 年也还有 173 亿, 1992 年仅在长江中游洪湖江段中 四大家鱼鱼苗径流量就有 16 亿之多! 且不说这个杯水车薪的放流数量, 其实, 放的再多也可能无济于事, 因为中下游干流中的饵料生物过于贫痊, 等待这些鱼苗的可能仅有无情的饥饿.

生态调度也被寄予了不切实际的希望. 曹文宣 ${ }^{[91]}$ 指出, “如果在长江上找不到几尾参加繁殖的亲鱼, 再 好的人造洪峰还是等于零. 所以, 长江的休渔和禁渔, 比人造洪峰更为迫切”. 笔者完全赞成前一句, 但仅部 分赞成后一句,因为休渔和禁渔虽能起到一定的改善作用,但亦无法真正扭转颓势.

在上游还有 12 个水生野生动物自然保护区, 23 个国家级水产种质资源保护区 ${ }^{[22]}$. 布庸置疑, 这些保护 区在维持上游物种多样性上能起到一定作用, 虽然远远不足以改变颓废的局面, 但至少可以守住一点地盘, 以免被我们的“大开发”损失殆尽.

如果对长江生物多样性危机成因进行粗略的估算, 节制闸和水电站等水利工程 “贡献”了七成, 酷渔乱 捕等其它因素 “贡献”了三成. 码头林立堤岸硬化导致的自然岸线丧失等也起到了推波助澜的作用, 因为绝 大部分鱼苗需在离岸 $10 \mathrm{~m}$ 以内的近岸生境中度过一段关键时刻 ${ }^{[92]}$. 当然, 假若制定和执行好渔业管理政 策, 酷渔乱捕的影响是可以较快消除, 而水利工程的影响则难以改变, 它对不少物种的影响是毁灭性的,像 人造洪峰这样的“生态调度” 不过是掩耳盗铃的伎俩罢了. 总体来看, 江豚、中华鲟、白鲟等诸多物种的绝灭 似乎在所难免.

如果不将长江干支流与附属湖泊的通道打开, 如果不将葛洲坝、三峡工程以及上游数以万计的水电站 拆除, 长江水系的生物多样性危机不会得到根本性解决, 但全面拆除这些水利工程又几乎是不可能的, 而所 谓的三峡大坝或其它水电站的生态调度 ${ }^{[93]}$ 、鱼道或人工放流等根本不可能解决这些问题. 在笔者看来, 这 些举措难以拯救高育之疾, 充其量能起到一点 “延缓”作用, 更贴切的说, 象征意义大于实际意义,一种“作 秀”罢了.

笔者当然赞成长江十年禁渔的主张, 但认为这还不够, 还必须在洞庭湖和鄱阳湖禁渔十年, 并对沿江阻 隔湖泊进行 “顺灌” ——在产漂流性卵鱼类繁殖季节, 当江水水位高于湖水时, 在育苗汛期开闸引水, 纳人鱼 苗, 而在秋冬季, 让成熟的亲鱼返回长江 (为此在河湖通道中必须禁捕), 以便翌年春季可以逆江上溯产卵繁 殖. 这样既可以提高两湖的渔业资源量, 也可为干流渔业资源提供充沛的补充, 从而使江豚的食物条件得到 大大的改善,同时还可减少捕鱼对江豚等的误杀,这也许是拯救江豚的唯一办法.

\section{6 以人为本一一为 “野蛮”撑腰}

有人划分了两种截然相反的生态观一一“生态野蛮” 和“生态愚昧”, 前者追求不计环境后果、只顾眼前 利益的掠夺性开发, 后者将人和自然完全对立, 认为保护生态环境就是人类什么也别做, 并将反坝者视为 “生态愚昧”, 并宣称 “加快水电建设、提高蓄水能力是我国建设生态文明的当务之急” ${ }^{[19]}$. 利奥波德 ${ }^{\left[{ }^{[83}\right]}$ 曾 说, “文明用各种新挑战、发明和经纪人, 把最基本的人一地球的关系搞得热闹非凡, 以致把意识也搞糊涂 了”.

人类社会的价值观永远都会是以人为本, 所有的动物都会以自己的种族为本, 只是人的能力最卓越故 得以统治大自然, 因此, 大自然中不可能做到众生平等. 人与自然的和谐相处往往只是一个口号, 没有哪个 物种会主观地去与别的种族和谐相处, 即便现象如此, 本质却是受制于自然调节的结果. 而对人的自然调节 往往只能通过灾难的形式, 即因果轮回, 否者我们不会敬畏自然. 对人来说, 人命肯定比动物 (譬如长江中的 豚类、鱼类)之命要重要得多, 保护在绝大多数时候也都必须给开发让路,或者按上面的说法就是, “愚昧” 必 须给“野蛮”让路. 水电对在陆地上生活的人每天呼吸的空气质量来说是绿色与安康, 但对很多水中生活的 鱼儿来说, 就是黑色与灾难.

在人类历史上, 征服者最终都将祸及自身, 因为在征服者这个角色中包含着这样一种意思: 他就是权 
威, 即只有这位征服者才能知道, 是什么在使这个共同体运转, 以及在这个共同体的生活中, 什么东西和什 么人是有价值的, 什么东西和什么人是没有价值的. 结果他总是什么也不知道, 所以这也就是为什么他的征 服最终只能招致自身的失败 ${ }^{[83]}$.

其实, 只有人才明白自己仅仅是进化旅途中的其它生物的同路者, 这应该使我们具有一种与同行的生 物被亲缘联系着的观念, 我们有生存的欲望, 也应该允许它们生存, 而且生物界是一个被各种关系编织出的 复杂而连续的系统. 人类现在是探险船的船长, 但人类本身已经不是这艘船唯一的探索目标 ${ }^{[83]}$.

\section{7 灭绝一一大已成舟}

一些生态学家在大自然的复杂性面前倒是谨小慎微,譬如 Ludwig 等 ${ }^{[85}$ 坦言, “政治家、资源管理者和利 用者不应该也不可能期望生态学研究会告诉他们应该怎样做. 这是因为对生态系统的认识过程往往是很慢 的, 等待科学研究获得完备的答案实际上是徒劳的; 对生态系统管理的决策必须依据当前的知识立即做出; 在很多自然系统中唯一的可以了解它们可持续性的有效方法就是开发它们”. 对长江这样一个全长达 6300 $\mathrm{km}$ 、流域面积 $\left(1.80 \times 10^{6} \mathrm{~km}^{2}\right)$ 占全国总面积的 $18.7 \%$ 、以及数千种水生生物在不断变化的气候与水沙背景下 极其复杂地相互作用的生态系统来说,生物及其生态过程对人类干扰的响应充满着不确定性,一些物种的 兴衰与命运需要在相当大尺度的时空演绎之后才会被人们所感知或察觉, 而此刻往往为时已晚, 因为木已 成舟.

遗憾的是, 对大自然的敬畏却被一些不懂生态的人痛批为肆无忌惮的神秘主义. 就如利奥波德 ${ }^{[83]}$ 所 说, “今天, 普通的公民都认为, 科学知道是什么在使这个共同体运转, 但科学家始终确信他不知道. 科学家 懂得, 生物系统是如此复杂, 以致可能永远也不能充分了解它的活动情况”. 从某种意义上来说, 河水中的生 死轮回及其隐藏的深刻寓意, 既在河流的演化历史中留有记录, 也镌刻在物种的进化历史之中, 但它经历了 数以千万年的变迁与累积, 大多数证据早已消逝,所形成的千古之谜决不会轻易让人知晓.

在此笔者并不讨论应该建坝还是拆坝, 但可以说, 水坝像把双刀剑, 利弊都很突出, 它造福人类的能力 无与伦比 (发电、蓄水、灌溉等), 但对一些生活在河流中的物种的打击也是毁灭性的, 而且两者不可调和. 我 只是想客观地评价它与长江水系生物多样性危机之间可能的因果关系, 如果这能为决策者与社会大众对水 坝生态效应的认知提供些许帮助, 就心满意足了.

针对长江的生物多样性危机, 笔者的看法是悲观的. 我们难以恢复中下游的江湖关系以使河水在干支 流、湖泊、沼泽、洲滩等构成的复杂水网系统中自由自在地漫流, 也无法疏通干支流的鱼类洄游通道. 因此, 我们根本不可能恢复原来的自然生命网络! 我们欢乐了, 而长江却哭泣了, 因为它耗费数百万年的时光辛 苦聿积起来的自然遗产,顷刻间将灰飞烟灭!

\section{8 长江的生物多样性需要生态文明的呵护与维持}

人是大自然的产物, 人的生存也倚赖于自然的生态过程, 尽管在人的眼中是那样的平庸, 而正是这些 “鱼、树、草” 及其复杂的相互关系才是我们得以雕刻出那种可称之为文明 “珍品” 的原材料, 但人并不能超 越大自然, 也得在自然历史的长河中漂流. 人只有犯罪后才进班房, 而鱼则被水坝无端贝禁. 我们不可以也 不必要榕干每一滴河水. 我们应该对大自然的原始性、复杂性和多样性给予尽可能多一点的呵护, 这并不是 人类的施舍或怜悯, 也是对人类自身的呵护,谁说一定不会遇上因果轮回呢? 当然, 这绝不是让我们重回蛮 荒的过去, 而是睿智地与自然和谐共存. 只有这样, 人才可以从动物野蛮的桎梏中挣脱出来, 才有超越野兽 的客观证据,才配得上“文明” 乃至“生态文明” 的称谓!

利奥波德 ${ }^{[83}$ 曾有一句名言: “我们蹂䟠土地, 是因为我们把它看成是一种属于我们的物品. 当我们把土 地看成是一个我们隶属于它的共同体时, 我们可能就会带着热爱与尊敬来使用它”. 对河流来说, 莫不是 如此.

习近平同志指出, “长江拥有独特的生态系统, 是我国重要的生态宝库. 当前和今后相当长一个时期, 要 把修复长江生态环境摆在压倒性位置, 共抓大保护, 不搞大开发”. 我们如何修复? 如何保护? 这些都是亟 待解决的重大科学问题. 对此的科学探索亦是生态学者义不容辞的历史使命.

\section{9 参考文献}

[ 1 ] Chen Yiyu ed. Promoting integrated management of river basin, and protecting the Yangtze River of life. China Water Re- 
sources, 2005, (8) : 10-12. [ 陈宜瑜. 推进流域综合管理, 保护长江生命之河. 中国水利, 2005，(8): 10-12.]

[ 2 ] Zhu Rulan. Biography of the Yangtze River. Baoding: Hebei University Press, 2006. [朱汝兰. 长江传. 保定: 河北大学 出版社, 2008.]

[ 3 ] Lowry WR. Restoring America's rivers. Washington, DC: Georgetown University Press, 2003. [劳里 WR. 大坝政治 学——恢复美国河流. 石建斌等译. 北京: 中国环境科学出版社, 2008.]

[ 4 ] Dong Yaohua, Wang Xiuli. Preliminary research on watershed division and stream order classification of the Yangtze River. Journal of Yangtze River Scientific Research Institute, 2013, 30: 1-5. [ 董耀华, 汪秀丽. 长江流域水系划分与河流分级 初步研究. 长江科学院院报, 2013, 30: 1-5.]

[ 5 ] Nelson JS. Fishes of the World. 4th. New York: John Wiley and Sons Inc. , 2006.

[ 6 ] Ormerod SJ. Current issues with fish and fisheries: editor's overview and introduction. Journal of Applied Ecology, 2003, 40: 204-213.

[ 7 ] Cao Wenxuan. Present status and protection strategy of fish resources in the Yangtze River. Jiangxi Fishery Sciences and Technology, 2011, 126: 1-4. [曹文宣. 长江鱼类资源的现状与保护对策. 江西水产科技, 2011, 126: 1-4.]

[ 8 ] Yu Zhitang. Preliminary evaluation of the impact of large hydro projects on fish resources in the Yangtze River (1). Reservoir Fisheries, 1988, (2) : 38-41. [ 余志堂. 大型水利枢纽对长江鱼类资源影响的初步评价 (一). 水利渔业, 1988, (2) : 38-41.]

[ 9 ] Fish Research Laboratory, Hubei Institute of Hydrobiology ed. Fishes of the Yangtze River. Beijing: Science Press, 1976. [湖北省水生生物研究所鱼类研究室. 长江鱼类. 北京: 科学出版社, 1976. ]

[10] Chen Yiyu, Cao Wenxuan, Zheng Ciying. Ichthyofauna of the Zhujiang River with a discussion on zoogeographical divisions for freshwater fishes. Acta Hydrobiologica Sinica, 1986, 10: 228-236. [陈宜瑜, 曹文宣, 郑慈英. 珠江的鱼类区 系及其动物地理区划的讨论. 水生生物学报, 1986, 10: 228-236.]

[11] Yang Xichen, Dou Hongshen, Wang Xianyi et al. Hydrological characteristics and resource utilization of lakes in the middle and lower reaches of Yangtze River. Natural Resources, 1982, (1): 47-54. [杨锡臣, 窦鸿身, 汪宪栕等. 长江中下 游地区湖泊的水文特点与资源利用问题. 自然资源，1982，(1) : 47-54.]

[12] Chang Jianbo, Cao Wenxuan. Fishery significance of the river-communicating lakes and strategies for the management of fish resources. Resources and Environment in the Yangtze Basin, 1999, 8(2) : 153-157. [ 常剑波, 曹文宣. 通江湖泊的 渔业意义及其资源管理对策. 长江流域资源与环境, 1999, 8(2) : 153-157.]

[13] Cho R. Removing dams and restoring rivers. News from the Earth Institute, Columbia University, 2011.

[14] Wang Haiying, Yao Tian, Wang Chuansheng et al. Threat and Pressure for the bio-diversity conservation in the area along the middle reaches of Changjiang River with suggestions on the countermeasure. Resources and Environment in the Yangtze Basin, 2004, 13: 429-433. [王海英, 姚畋, 王传胜等. 长江中游水生生物多样性保护面临的威胁和压力. 长江流 域资源与环境, 2004, 13: 429-433.]

[15] Yi Shui, Fan Xiao. The anti dam movement is in the world. Chinese National Geography, 2003, (10): 88-99. [易水, 范 晓. 反水坝运动在世界. 中国国家地理, 2003, (10): 88-99.]

[16] Struck D. Setting rivers free: As dams are torn down, nature is quickly recovering. Christian Science Monitor, 2016.

[17] Wang Ruonan, Wu Wenqiang, Peng Wenqi et al. Dynamic seismic stability analysis of erect structure considering soil stratigraphic. Journal of China Institute of Water Resources and Hydropower Research, 2015, 13(3) : 222-232. [王若男, 吴 文强, 彭文启等. 美国百年拆坝历史回顾. 中国水利水电科学研究院学报, 2015, 13(3) : 222-232.]

[18] Shui Bo. Out of the misunderstanding of dam demolition. People's Daily Online (www.people.com.cn), 2005. [水博. 走 出拆坝的误区. 人民网 (www.people.com.cn), 2005.]

[19] Wang Yilan. It is no good doing demonization of hydropower development-In order to build "ecological civilization", we must first step out of the misunderstanding of “ecological ignorance”. China Economic Weekly, 2016, (27): 78-81. [王 亦楠. 妖魔化水电开发要不得——“建设生态文明”须先走出 “生态愚昧” 的认识误区. 中国经济周刊, 2016, (27) : 78-81.]

[20] Yue Peiqi, Chen Yiyu eds. China red data book of endangered animals. Beijing: Science Press, 1998. [乐佩琦, 陈宜瑜. 中国濒危动物红皮书: 鱼类. 北京: 科学出版社, 1998.]

[21] Wang Song, Xie Yan eds. China species red list. Vol. I. Red List. Beijing: Higher Education Press, 2004. [汪松, 解炎. 中国物种红色名录: 第一卷. 红色名录. 北京: 高等教育出版社, 2004.]

[22] Xu Wei, Yang Zhi, Qiao Ye. Evaluation on protection priority of special fishes in hydropower development of upper Yan- 
gtze River. Yangtze River, 2013, 44: 109-112. [徐薇, 杨志, 乔晔. 长江上游河流开发受威胁鱼类优先保护等级评 估. 人民长江, 2013, 44: 109-112.]

[23] Chen Jin ed. A journey to the mysterious Three Rivers Headwaters region. Wuhan: Changjiang Press, 2015. [陈进. 神秘 的三江源之旅. 武汉: 长江出版社, 2015.]

[24] Zhang Shalong, Hou Yiqun, Wang Longtao et al. Swimming performance and swimming behavior of Schizothorax dolichone$m a$ Herzenstein. Freshwater Fisheries, 2014, 44: 32-37. [张沙龙, 侯轶群, 王龙涛等. 长丝裂腹鱼的游泳能力和游泳 行为研究. 淡水渔业, 2014, 44: 32-37.]

[25] Cao Liang, Zhang E, Zang Chunxin et al. Evaluating the status of China's continental fish and analyzing their causes of endangerment through the red list assessment. Biodiversity Science, 2016, 24: 598-609. [ 曹亮, 张鹗, 藏春金等. 通过红 色名录评估研究中国内陆鱼类受威胁现状及其成因. 生物多样性, 2016, 24: 598-609.]

[26] Liu Jiankang, He Biwu eds. Cultivation of the Chinese freshwater fishes (third edition). Beijing: Science Press, 1992. [刘建康，何碧梧. 中国淡水鱼类养殖学(第三版). 北京: 科学出版社, 1992.]

[27] Survey Team of Spawning Grounds of Domestic Fishes in Changjiang River. A survey on the spawning grounds of the "four famous Chinese carps" in the Changjiang River after dammed by the key water control project at Gezhouba. Journal of Fisheries of China , 1982, 6: 287-305. [长江四大家鱼产卵场调查队. 葛洲坝水利枢纽工程截流后长江四大家鱼产卵场 调查. 水产学报, 1982, 6: 287-305.]

[28 ] Niu Xinqiang, Tan Peilun. Studies on biological regulation of Three Gorges Project. China Water Resources, 2006, 14: 810. [钮新强, 谭培伦. 三峡工程生态调度的若干探讨. 中国水利, 2006, 14: 8-10.]

[29] Jiang Wei. Studies on Fish early resources in the main stream of state-levelnatural protection area for rare and endemicfishes in the upper Yangtze Rive[Dissertation]. Wuhan: Institute of Hydrobiology, CAS, 2009. [姜伟. 长江上游珍稀特有鱼 类国家级自然保护区干流江段鱼类早期资源研究 [学位论文]. 武汉: 中国科学院水生生物研究所, 2009.]

[30] Bai Haixia, Peng Qidong, Lo Chong et al. A summary of topographical characteristics of the four major Chinese carps' spawning grounds and hydrodynamic conditions for natural propagation in the Yangtze River. Journal of China Institute of Water Resources and Hydropower Research, 2014, 12: 250-257. [ 柏海霞, 彭期冬, 李肿等. 长江四大家鱼产卵场地形 及其自然繁殖水动力条件研究综述. 中国水利水电科学研究院学报, 2014, 12: 250-257.]

[31] Zhu Bin, Zheng Haitao, Qiao Ye et al. Fish stocking program in the Yangtze River. Chinese Fisheries Economics, 2009, 27: 74-87. [ 朱滨, 郑海涛, 乔华等. 长江流域淡水鱼类人工繁殖放流及其生态作用. 中国渔业经济, 2009, 27: 74-87.]

[32] Xie Ping ed. Silver carp and bighead, and their use in the control of algal blooms. Beijing: Science Press, 2003. [谢平. 鲢、鳙与藻类水华控制. 北京: 科学出版社, 2003.]

[33] Chen Yiyu. The skull of Elopichthys bambusa and its adaptation to predatory habit. Oceanologia et Limnogia Sinica, 1980, 11：169-172. [ 陈宜瑜. 鳡鱼的颅骨结构及其对掠食生态的适应性. 海洋与湖沼, 1980, 11: 169-172.]

[34] Webber T. Huge, once-hated fish now seen as weapon against Asian carp. Pantagraph: Associated Press, 2016.

[35] Cassens I, Vicario S, Waddell VG et al. Independent adaptation to riverine habitats allowed survival of ancient cetacean lineages. Proceedings of the National Academy of Sciences, 2000, 97: 11343-11347.

[36] Liu Renjun. Ecological adaptation and resource protection of Lipotes vexllifer. Fisheries Science \& Technology Information, 1980，(5)：18-19. [刘仁俊. 白鱆豚的生态适应与资源保护. 水产科技情报，1980，(5)：18-19.]

[37] Chen Peixun, Liu Peilin, Liu Renjun et al. The distribution, ecology, behavior and protection of the dophins in the middle reach of Chang Jiang River (Wuhan-Yueyang). Oceanologia et Limnogia Sinica, 1980, 11: 73-84. [ 陈佩薰, 刘沛霖, 刘仁俊等. 长江中游 (武汉一岳阳江段) 豚类的分布、生态、行为和保护. 海洋与湖沼, 1980, 11: 73-84.]

[38] Chen Peixun, Lin Keji, Hua Yuanyu. Preliminary study of biological characteristics of Lipotes vexillifer. Acta Hydrobiologica Sinica, 1985, 9: 176-185. [陈佩薰, 林克杰, 华元渝. 白鮆豚生物学特征的初步研究. 水生生物学报, 1985, 9: 176-185.]

[39] Chen Peixun, Liu Renjun, Wang Ding et al eds. Biology, rearing and protection of Baiji. Beijing: Science Press, 1997. [陈佩薰, 刘仁俊, 王丁等. 白暨豚生物学及饲养与保护. 北京: 科学出版社, 1997.]

[40] Hua Yuanyu, Zhang Jian. The status of population size of the Baiji, Lipotes vexllifer, and the analysis of causes of their rapid decrease. Journal of Nanjing Normal University: Natural Science, 1993, 16: 64-71. [华元渝, 张建. 白暨豚自然群体 数量及其锐减原因的分析. 南京师大学报: 自然科学版, 1993, 16: 64-71.]

[41] Wang Ding, Wang Kexiong, Liu Renjun et al. A preliminary study on the acoustic behavior and auditory sensitivity of $L i-$ 
potes vexillifer. Natural Science Journal of Xiangtan University, 1989, 11: 116-121. [王丁, 王克雄, 刘仁俊等. 白暨豚 声行为及听觉灵敏度的初步研究. 湘潭大学自然科学学报, 1989, 11: 116-121.]

[42] Zhou Kaiya, Qian Weijuan, Liu Yuemin. Studies on the distribution of Baiji, Lipotes vexillifer. Acta Zoologica Sinica, 1977, 23: 72-79. [周开亚, 钱伟娟, 李悦民. 白鴊豚的分布调查. 动物学报, 1977, 23: 72-79.]

[43] Hua Yuanyu, Zhang Guocheng, Zhao Qinqzhong et al. Preliminary study of dwelling area of Lipotes vexillifer and their crowd. Environmental Science \& Technology, 1986, 35: 2-5. [华元渝, 张国成, 赵庆中等. 白鴊豚栖息活动区及其群 体活动的初步研究. 环境科学与技术, 1986, 35: 2-5.]

[44] Hua Yuanyu, Xiang Chengsheng, Dong Mingli et al. Study on the sexual and feeding behavior of the captured black finless porpoise (Neophocaene phocaenoides) in Yangtze River. Resources and Environment in the Yangtze Basin, 1994, (3): 141-146. [华元渝, 项澄生, 董明利等. 长江江豚的交配行为和摄食行为的研究. 长江流域资源与环境, 1994, (3) : 141-146.]

[45] Yu Daoping, Wang Jiang. Variations of Baiji's ecological environment and behavior in the reaches of Tongling of the Yangtze River. Journal of Zhejiang Ocean University: Natural Science, 1999, 18: 227-231. [于道平, 王江. 铜陵江段白暨 豚生态环境与行为的变化. 浙江海洋学院学报: 自然科学版, 1999, 18: 227-231.]

[46] Zhang X, Wang D, Liu R et al. The Yangtze River dolphin or baiji (Lipotes vexillifer): Population status and conservation issues in the Yangtze River, China. Aquatic Conservation: Marine and Freshwater Ecosystems, 2003, 13: 51-64.

[47 ] Zhao X, Barlow J, Taylor BL et al. Abundance and conservation status of the Yangtze finless porpoise in the Yangtze River, China. Biological Conservation, 2008, 141: 3006- 3018.

[48] Hao Yujiang, Wang Kexiong, Han Jiabo et al. Marine mammal researches in China. Acta Theriologica Sinica, 2011, 31: 20-36. [郝玉江, 王克雄, 韩家波等. 中国海兽研究概述. 兽类学报, 2011, 31: 20-36. ]

[49] Zhang Xianfeng, Liu Renjun, Zhao Qingzhong et al. The population of finless propoise in the middle and lower reaches of Yangtze River. Acta Theriologica Sinica, 1993, 13: 260-270. [张先锋, 刘仁俊, 赵庆中等. 长江中下游江豚种群现状 评价. 兽类学报, 1993, 13: 260-270.]

[50] Birstein VJ, Hanner R, DeSalle R. Phylogeny of the Acipenseriformes: cytogenic and molecular approaches. Environmental Biology of Fishes, 1997, 48: 127-155.

[51] Yu Zhitang, Xu Yungan, Deng Zhonglin et al eds. Study on reproductive ecology of Zhonghua sturgeon (Acipenser sinensis Gray) downstream of the Gezhouba Hydroelectric Project. Transactions of the Chinese Ichthyological Society (Vol. 5). Beijing: Science Press, 1986: 1-14. [余志堂, 许蕴玕, 邓中粦等. 葛洲坝枢纽下游中华鲟繁殖生态的研究. 鱼类学论 文集(第五辑). 北京: 科学出版社, 1986: 1-14.]

[52] Wei Q, Ke F, Zhang J et al. Biology, fisheries, and conservation of sturgeons and paddlefish in China. Environmental Biology of Fishes, 1997, 48: 241-255.

[53] Zhuang Ping, Wang Youhuai, Li Shengfa et al eds. Fishes of the Yangtze estuary. Shanghai: Shanghai Scientific \& Technical Publishers, 2006. [ 庄平, 王幼槐, 李圣法等. 长江口鱼类. 上海: 上海科学技术出版社, 2006. ]

[54] Xin D, Zonglin D, Mingyan C. Spawning population characteristics of Acipenser sinensis in Yangtze River just below Gezhoba Dam. In: Williot P ed. Proceedings of the First International Symposium on sturgeons. Bordeaux (Gironde, France), 1991: 235-242.

[55] Environmental Evaluation Department of Chinese Academy of Sciences and Changjiang Water Resources Protection Institute. Report on environmental impacts of the Three Gorges hydro project at the Yangtze River, 1991. [中国科学院环 境评价部和长江水资源保护研究所. 长江三峡水利枢纽环境影响报告书, 1991.]

[56] Wu Jinming, Wang Chengyou, Zhang Shuhuan et al. From continuous to occasional: Small-scale natural reproduction of Chinese sturgeon occured in the Gezhouba spawning ground, Yichang, China. Journal of Fishery Sciences of China, 2017, 24: 425-431. [吴金明, 王成友, 张书环等. 从连续到偶发: 中华鲟在葛洲坝下发生小规模自然繁殖. 中国水产科 学, 2017, 24: 425-431.]

[57] Sun Li, Li Jilong, Chen Daqing et al. A prelimary study on fish geographic distribution in upper reach of Yangtze River based on GIS. Frshwater Fisheries, 2008, 38: 40-44. [孙璐, 李继龙, 陈大庆等. 基于 GIS 的长江上游鱼类地理分布 特征研究. 淡水渔业, 2008, 38: 40-44.]

[58] Xie P. Three-Gorges Dam: risk to ancient fish. Science, 2003, 302: 1149.

[59] Liu Cheng. Notes on Psephurus gladius. Fisheries Science \& Technology Information, 1979，(1)：13-14. [刘成汉. 有关 白鲟的一些资料. 水产科技情报, 1979, (1)：13-14.] 
[60] Deng Zhonglin, Yu Zhitang, Zhao Yan et al. Evaluation of the impact of the Three Gorges Project on Psephurus gladius and Myxocyprinus asiaticus in the Yangtze River and the study of their resources protection. In: Collected papers on studies on the ecological and environmental impacts of the Three Gorges Project at the Yangtze River and their countermeasures. Beijing: Science Press, 1987: 42-52. [邓中粦, 余志棠, 赵燕等. 三峡水利枢纽对长江白鲟和胭脂鱼影响的评价及资 源保护研究. 见: 长江三峡工程对生态与环境影响及其对策研究论文集. 北京: 科学出版社, 1987: 42-52.]

[61] Lu Xuebao, Ni Yong, Rao Jun. Resources status and research progress of Acipenser dabryanus. Fisheries Science \& Technology Information, 2012, 39: 251-257. [鲁雪报, 倪勇, 饶军等. 达氏鲟的资源现状及研究进展. 水产科技情报, 2012, 39: 251-257. ]

[62] Qi Delin, Chao Yan, Yang Chen et al. Cloning of mitochondrial cytochrome b gene of Hucho bleekeri and its phylogenetic relationships in subfamily Salmoninae. Sichuan Journal of Zoology, 2009, 28: 805-809. [祁得林, 昆燕, 杨成等. 川陕 哲罗鲑 $C y t b$ 基因克隆及其在鲑亚科中的系统发育关系. 四川动物, 2009, 28: 805-809.]

[63] Shen Zhixin, Tang Wen, Li Kemao. The survival crisis and protection countermeasures ofHucho bleekeri. Frshwater Fisher$i e s, 2005,35:$ 25-28. [ 申志新, 唐文家, 李柯禁. 川陕哲罗鲑的生存危机与保护对策. 淡水渔业, 2005, 35: 25-28.]

[64] Ru Huijun, Li Yunfeng, Shen Ziwei et al. Distribution and habitat character of Hucho bleekeri in the Dadu River basin. Resources and Environment in the Yangtze Basin, 2015, 24: 1779-1785. [茹辉军, 李云峰, 沈子伟等. 大渡河流域川陕 哲罗鮏分布与栖息地特征研究. 长江流域资源与环境, 2015, 24: 1779-1785.]

[65] Wu Jinming, Yang Huanchao, Shao Jian et al. Habitat environmental characteristics of Brachymystax lenok tsinlingensis. Acta Hydrobiologica Sinica, 2017, 41: 214-219. [吴金明, 杨焕超, 邵俭等. 秦岭细鳞鮏栖息地环境特征研究. 水生 生物学报, 2017, 41: 214-219.]

[66] Li Kemao. Suggestions on the assessment of aquatic life and protection of fish proliferation in the Three Rivers Headwaters region. China Fisheris, 2007, 38(5) : 72-73. [李柯惁. 三江源区水利工程对水生生物影响评价和鱼类增殖保护建 议. 中国水产, 2007, 38(5): 72-73.]

[67] Liu Shaoping, Chen Daqing, Duan Xinbin et al. The resources status Quo and protection strategies on Chinese shad. Acta Hydrobiologica Sinica, 2002, 26: 679-684. [刘绍平, 陈大庆, 段辛斌等. 中国鲥鱼资源现状与保护对策. 水生生物 学报, 2002, 26: 679-684.]

[68] Xie Ping ed. Scaling ecology to understand natural design of life systems and their operations and evolutions-Integration of ecology, genetics and evolution through reproduction. Beijing: Science Press, 2013. [谢平. 从生态学透视生命系统的 设计、运作与演化一一生态、遗传和进化通过生殖的整合. 北京: 科学出版社, 2013. ]

[69] Tang Qicheng, Xiong Yi eds. River hydrology in China. Beijing: Science Press, 1998. [汤奇成, 熊怡. 中国河流水文. 北京: 科学出版社, 1998.]

[70 ] Jiang Jiahu, Dou Hongshen eds. The five largest freshwater lakes in China. Hefei: University of Science and Technology of China Press, 2003. [姜加虎, 窦鸿身. 中国五大淡水湖. 合肥: 中国科学技术大学出版社, 2003.]

[71] Liang Yanlin, Li Xichun, Zheng Ying. Study on runoff variation characteristics of Dongting Lake. China Rural Water and Hydropower, 2015, (5): 67-71. [梁亚琳, 黎昔春, 郑颖. 洞庭湖径流变化特性研究. 中国农村水利水电, 2015, (5): 67-71.]

[72] Wang Xue, Zhao Xuefeng, Zhao Xuejun. Comparative analysis of back-flow characteristics of Poyang Lake before and after operation of Three Gorges project. Journal of Changjiang Institute of Technology, 2017, 34(1) : 9-12. [王雪, 赵学峰, 赵学军. 三峡工程运行前后鄱阳湖倒灌特性对比分析. 长江工程职业技术学院学报, 2017, 34(1): 9-12.]

[73] Chen Yiyu, Chen Wei. Notes on some morphological and anatomical features of the white-flag dolphin, Lipotes vexillifer Miller. Acta Hydrobiologica Sinica , 1975, 5(3): 360-368. [陈宜瑜, 陈炜. 关于白㽬豚的一些形态解剖资料. 水生生 物学集刊, 1975, 5(3): 360-368.]

[74] Xiao Wen, Zhang Xianfeng. A preliminary study on the population size of Yangtze finless propoise in Poyang Lake, Jiangxi. Chinese Biodiversity, 2000, 8(1): 106-111. [肖文, 张先锋. 截线抽样法用于鄱阳湖江豚种群数量研究初报. 生 物多样性, 2000, 8(1): 106-111.]

[75] Liu Lei, Xu Zuoyang, Yang Xue et al. Population size, distribution and behavioral characteristics of the Yangtze finless porpoise in the low water period of Poyang Lake. Journal of Nanchang University: Natural Science, 2016, 40: 276-280. [刘否, 胥左阳, 杨雪等. 枯水期鄱阳湖重点水域长江江豚种群数量、分布及行为特征. 南昌大学学报: 理科版, 2016, 40: 276-280.] 
[76] Liao Fuchu, He Wang, Huang Xiangrong et al. Studies on present situation and change trend of Dongting Lake fishery resources and environment. Acta Hydrobiologica Sinica, 2002, 26: 623-627. [廖伏初, 何望, 黄向荣等. 洞庭湖渔业资源 现状及其变化. 水生生物学报, 2002, 26: 623-627.]

[77] Li Hongbing, Xu Deping. Characteristics and causes of resource changes of the four domestic carps in Dongting Lake. Inland Fisheries, 2008, 33(6): 34-36. [李红炳，徐德平. 洞庭湖“四大家鱼”资源变化特征及原因分析. 内陆水产, $2008, \mathbf{3 3}(6)$ : 34-36.]

[78] Li Jieqin. Ecologicalstudy on fish community and conservation strategies in Dongting Lake[Dissertation]. Changsha: Central South University of Forestry \& Technology. [李杰钦. 洞庭湖鱼类群落生态研究及保育对策 [学位论文]. 长沙: 中 南林业科技大学, 2013.]

[79] Qian Xiner, Huang Chungen, Wang Yamin. The status of fishery resources of Poyang Lake and its environmental monitoring. Acta Hydrobiologica Sinica, 2002, 26(6) : 612-617. [ 钱新娥, 黄春根, 王亚民等. 鄱阳湖渔业资源现状及其环 境监测. 水生生物学报, 2002, 26(6): 612-617.]

[80] Huang Xiaoping, Gong Yan. Study on the current situation of fishery resources and conservation countermeasures in Poyang Lake. Jiangxi Fishery Sciences and Technology, 2007, (4): 2-6. [黄晓平, 龚雁. 鄱阳湖渔业资源现状与养护对策研 究. 江西水产科技, 2007, (4): 2-6.]

[81] Wu Bin, Fang Chunlin, Gan Jiangying. Present situation analysis and ecological economic prospect of the four domestic carps in Poyang Lake. China Fisheris, 2014, (10) : 27-28. [ 吴斌, 方春林, 甘江英. 鄱阳湖“四大家鱼” 的现状分析 与生态经济前景. 中国水产, 2014, (10): 27-28.]

[82] Chen Jiakuan, Lai Xijun, Jiang Yong et al. Is Poyang Lake water control project for ecology or pseudo-ecology, or a debate between development and protection? China Weekly, 2017, (1) : 54-59. [ 陈家宽, 赖锡军, 蒋勇等. 鄱阳湖水利枢纽 “为”生态还是“伪”生态? 亦或开发保护之争? 中国周刊, 2017, (1) : 54-59.]

[83] Leopold A. A sand county almanac: And sketches here and there. New York: Oxford, 1949. [利奥波德 A. 沙乡年鉴. 侯 文萬译. 长春: 吉林人民出版社, 1997.]

[84] Fu Bojie, Zhang Liwei. Land-use change and ecosystem services:Concepts, methods and progress. Progress in Geography, 2014, 33: 441-446. [傅伯杰, 张立伟. 土地利用变化与生态系统服务: 概念、方法与进展. 地理科学进展, 2014, 33: 441-446.]

[85] Ludwig D, Hilborn R, Walters C. Uncertainty, resource exploitation, and conservation: Lessons from history. Science, 1993, 260 : 17-36.

[86] Ba Xiaofang. Connecting rivers and lakes. Centurial Trip, 2004, (4) : 11-15. [巴晓方. 连通江河湖沼. 世纪行, 2004, (4) : 11-15.]

[87] Jiang Zhigang, Ma Keping eds. The principle of conservation biology. Beijing: Science Press, 2014. [蒋志刚, 马克平. 保护生物学原理. 北京: 科学出版社, 2014.]

[88] Ma Keping. Conservation biology, conservation ecology and biodiversity science. Biodiversity Science, 2016, 24: 125-126. [马克平. 保护生物学、保护生态学与生物多样性科学. 生物多样性, 2016, 24: 125-126.]

[89] Chen Fengxue. The historical opportunity of wetland protection and restoration under the protection of the Yangtze River. China Weekly, 2017, (1) : 20-21. [陈凤学. 长江大保护视野下湿地保护与恢复的历史机遇. 中国周刊, 2017, (1) : 20-21.]

[90] Yu Guirui. A conceptual framework and the ecological basis for ecosystem management. Chinese Journal of Applied Ecolo$g y, 2001,12(5)$ : 787-794. [于贵瑞. 生态系统管理学的概念框架及其生态学基础. 应用生态学报, 2001, 12(5): 787-794. ]

[ 91 Cao Wenxuan. If the Yangtze River can rest: Talking about the protection of fish in the Yangtze River. China Three Gorges, 2008，12: 148-157. [曹文宣. 如果长江能休息: 长江鱼类保护纵横谈. 中国三峡: 人文版, 2008, 12: 148-157.]

[92] Chang Jianbo, Deng Zhonglin, Zhang Guohua et al. "Filling water and accommodating fry" in Honghu Lake: Possibility and ecological benefits. In: Chen Yiyu, Xu Yungan et al eds. Hydrobiology and resources exploitation in Honghu Lake. Beijing: Science Press, 1995: 220-231. [ 常剑波, 邓中粼, 张国华等. 洪湖灌江纳苗的可行性及效益评价. 见: 陈宜 瑜, 徐蕴玕等编. 洪湖水生生物及其资源开发. 北京: 科学出版社, 1995: 220-231.]

[93] Wang Yu, Zhai Zhennan, Dai Lingquan. Study on joint eco-operation of cascade reservoirs for compensation of hydrodynamic environment of Chinese Sturgeon spawning ground. Water Resources and Hydropower Engineering, 2017, 48: 91-97. [王显, 翟振男, 戴凌全. 补偿中华鲟产卵场水动力环境的梯级水库联合生态调度研究. 水利水电技术, 2017, 48: 91-97.] 